\title{
Modeling and simulation of inhomogeneities in a 18650 nickel-rich, silicon-graphite lithium-ion cell during fast charging
}

\author{
Sturm, J. ${ }^{a}, *$, Rheinfeld, A. ${ }^{a}$, Zilberman, I. ${ }^{a}$, Spingler, F. B. ${ }^{a}$, Kosch, S. ${ }^{a}$, \\ Frie, F. ${ }^{b}$, Jossen, A. ${ }^{a}$ \\ ${ }^{a}$ Technical University of Munich (TUM), Institute for Electrical Energy Storage \\ Technology (EES), Arcisstrasse 21, 80333 Munich, Germany \\ ${ }^{b}$ Aachen University of Technology (RWTH), Institute for Power Electronics and \\ Electrical Drives (ISEA), Jägerstrasse 17-19, 52066 Aachen, Germany
}

\begin{abstract}
Recent high-energy lithium-ion batteries contain highly densified electrodes, but they are expected to endure fast charging without safety compromises or accelerated aging. To investigate fast charging strategies, we use a multidimensional model consisting of several newman-type electrochemical models (p2D) coupled to an electrical-thermal cell domain model. Open-circuit potential, infrared thermography and calorimetry experiments of a high-energy 18650 NMC-811/SiC lithium-ion cell are used for model parameterization and validation. First, a single p2D model is used to compare the charging rate capabilities of NMC-811/SiC and NMC-111/graphite cells. We assess the modeling error of the single p2D model relative to the multi-dimensional model as a function of tab design. The multi-dimensional model is then used to study different tab and electrode designs regarding their susceptibility to lithium plating, which is evaluated based on local anode overpotential and
\end{abstract}

\footnotetext{
*Corresponding author: johannes.sturm@tum.de
} 
local temperature. High-rate charging current profiles that minimize the risk of lithium plating are derived by implementing an anode potential threshold. We show that a state of charge beyond $60 \%$ can be reached in less than 18 $\min$.

Keywords: lithium-ion battery, nickel-rich, lithium plating, fast charging, multi-dimensional model, pseudo-two dimensional model

\section{Introduction}

Even if state of the art lithium-ion technologies offer the highest energy and power density among other battery chemistries, the requirements for the next decade [1] of large stationary storage systems and automotive applications exceed available capabilities. Extended operational performance will be required such as offering a range of more than $300 \mathrm{~km} \mathrm{[2]} \mathrm{for} \mathrm{a} \mathrm{full-electric}$ vehicle while maintaining lifetime and safety [3]. Preliminary estimates target at $300 \mathrm{Wh} \mathrm{kg}^{-1}$ on cell level [1,4] to achieve energy densities on battery pack level around $250 \mathrm{Wh} \mathrm{kg}^{-1}$. Referring to the geometrical format and the capacity of the cell, current automotive applications incorporate already larger-sized cells [5] via increasing the width and length of the electrodes and/or the coating thicknesses of the composites with standard chemistries such as Graphite (C), Nickel Manganese Cobalt (NMC) or Nickel Cobalt Aluminum (NCA) oxides [3]. Small formats such as the 18650 cell offer limited geometrical space but higher intrinsic safety due to their thermal behavior compared to large-sized cell formats and higher capacities are achieved through advancements on the electrode level $\left(>600 \mathrm{Wh} \mathrm{kg}^{-1}\right)$ and active material level $\left(>700 \mathrm{Wh} \mathrm{kg}^{-1}\right)$ via highly densified electrodes yielding to low 
porosities $(<20 \%)$ and/or employing high-capacity active materials [1].

In order to meet these requirements [3], layered oxide-types such as highenergy NMC, nickel-rich NMC-types (e.g. NMC-811) and NCA [1] appear to be the most suitable choice in combination with silicon doped graphite ( $\mathrm{SiC}$ ) anodes [4]. To increase the intrinsic capacity of NMC-type electrodes, the content of nickel, manganese and cobalt is varied from an equalized, standard composition (i.e. NMC-111) to nickel-rich oxides which content nickel beyond $80 \mathrm{wt} \%$ [6]. Specific capacities up to $275.5 \mathrm{mAhg}^{-1}$ [7] at a cut-off voltage of $5 \mathrm{~V}$ and approximately $200 \mathrm{mAh} \mathrm{g}^{-1}$ [6] at $4.3 \mathrm{~V}$ are achievable for a NMC-811 cathode and despite the possible capacity fading [7] due to gasing and oxygen release from the host lattice seen above $4 \mathrm{~V}$, nickel-rich active materials turn out to provide high-capacity electrodes.

In terms of the anodic active material, silicon containing graphite compounds offer capacities $>400 \mathrm{mAhg}^{-1}[8,9,10,11]$ which exceed the standard graphite anodes $\left(372 \mathrm{mAh}^{-1}[12,13,14]\right)$. Doping graphite with small amounts of silicon (1:93 wt\% for Si:C) increases the specific capacity significantly [8]. However, the volumetric expansion of silicon during lithiation is a crucial issue. As the volumetric expansion of pure silicon $(\approx 400 \%$ [15]) can only partly be accommodated by the graphitic matrix [11], decreasing the size of the particles [16], incorporating silicon nanowires [15] or using coatings with carbon [17] dilute the overall volume expansion [18] and limit the lithiation window of the Si component which makes silicon doped graphite to an appropriate high-capacity active material for anodes.

Considering nickel-rich and silicon doped graphite materials on the electrode level, an increase from $\approx 340 \mathrm{Wh} \mathrm{kg}^{-1}$ to $>600 \mathrm{Wh} \mathrm{kg}^{-1}$ [1] is attainable when 
the morphology [1], coating thicknesses [5] and the amount of inactive additives [19] are optimized. Standard electrodes reveal porosities of approximately $35 \%$ [1], whereas high-energy electrodes reveal porosities even below $20 \%$, which may enhance unwanted liquid mass transport limitations [20] and lower the charge and discharge-rate capability of the cell.

In short, next generation high-energy electrodes will incorporate high-capacity active materials (e.g. NMC-811/SiC) and low porous electrodes beside thicker coatings or longer electrodes.

In this work, a commercial 3.35 Ah NMC-811/SiC (INR18650-MJ1, LG Chem [21]) lithium-ion battery is characterized via calorimetry, infrared thermography and open-circuit potential (OCP) experiments. Based on the experimental part, a newman-type [22] pseudo-two dimensional (p2D) model and a Multi-Dimensional Model (MuDiMod) [23, 24, 25, 26] are parameterized and validated for a simulation study on the latest, widley discussed field of fast charging $[27,28,29,30]$. In this matter, charge-rate capability and tendency of lithium plating is analyzed for the high-capacity and a standard NMC111/C material in highly and moderatly densified electrodes. The MuDiMod is used to evaluate different tab designs in terms of lithium plating susceptibility for the INR18650-MJ1 (MJ1) cell during high-rate constant-current charging and based on that, cell voltage as well as local anode potential thresholds are used to derive improved fast charging protocols. The charging simulation results are used to evaluate the modeling error of the single p2D model relative to the MuDiMod as a function of tab design. 


\subsection{Local experimental investigation of lithium-ion cells}

Experimental investigation of a cell's local behavior such as changing concentrations or potentials in the electrolyte and the active particles throughout or even along the electrodes requires in-situ or in-operando techniques which are often associated with costly experimental equipment such as X-ray tomography [31], neutron-powder diffraction [32] or focused ion-beam scanning electron microscopy [33]. Using less complex test procedure such as electrochemical impedance spectroscopy (EIS), current density and local potential distribution along the electrode was investigated towards the influence of alternating excitation currents, temperature, tab pattern and frequency for a modified $26650 \mathrm{LFP} / \mathrm{C}$ cell with four tabs [34]. Subsequently, a single layered NMC/C pouch cell with several measurement tabs along the electrode revealed the dependency of local current peaks towards the electrode OCPs and was used to validate the MuDiMod [24], which is used in this work. Cells without multi-tab design can be modified with reference electrodes to measure local potentials and to correlate lithiation levels to the global state of charge (SoC) of the cell [35]. Beside measuring local potentials [36], temperature sensors [37] in the core of the cell or even optical fibres with Bragg Grating [38] are implemented in the cell to measure local temperatures such as the core-temperature.

However, the additional devices may alter the cell's behavior even if model validation could enormously benefit. Generally, these experimental investigations mostly work on a laboratory scale whereas for application purposes, none of these techniques are suitable due to complex measurement techniques and possible altering of the cell's behavior. However, simulation provides 
an efficient and safe alternative to experimental techniques and may profit through experimental validation in future works.

\subsection{Multi-dimensional simulation of lithium-ion cells}

Multi-dimensional modeling frameworks reveal reliable results [39, 40] to analyze the performance of lithium-ion batteries looking at rate-capability [41], heat generation rate [42] or the non-uniformity of current density along the electrodes related to non-optimized electrical design [43]. These models solve for electrochemical, electrical and thermal mechanisms on their relevant length scales such as particle size and electrode thickness (p2D), current collector length and width (2D) and the total jelly roll/electrode stack (3D). The size and tab pattern of the current collectors mainly influences the gained energy density [44] from the cell and is analyzed in this work via the MuDiMod for a high-energy 18650 cells with an electrode size of $5.8 \times 61.5 \mathrm{~cm}$. In literature, electrode sizes of $4.6 \times 13.8 \mathrm{~cm}$ were analyzed with a 3D electrochemical-thermal model for a $\mathrm{NCA} / \mathrm{C}$ cell [45] to investigate single- and double-sided cooling for six connected cells and suggested the evaluation of design parameters (i.e. cathode thickness) via the influence on the thermal cell behavior. Model validity is limited as uniform electrode utilization was assumed, which may not be appropriate in case of a single-side cooling condition.

Analysing larger electrode sizes of $11 \times 111 \mathrm{~cm}$ [46] for a $\mathrm{LFP} / \mathrm{C}$ cell via a 3D electrochemical-thermal model, the highest risk of lithium plating appeared close to the negative current collector tabs.

Analyzing the electrical configuration via continuum based models [43] for a $\mathrm{NCA} / \mathrm{C}$ cell, different tab patterns along a $3.23 \mathrm{~m}$ electrode revealed an 
increase of cell impedance and non-uniformity of reaction kinetics, when decreasing the number of tabs.

Large $20.5 \times 512 \mathrm{~cm}$ electrode sizes were investigated for a NMC/C cell via a 3D electrochemical-thermal model [44] under applying different tab patterns. A correlation of the cell specific energy density and the non-uniformity of the current density was proposed.

Previous works dealt with standard active materials (e.g. NMC-111/C), whereas multidimensional analysis of high-capacity active materials (i.e. NMC$811 / \mathrm{SiC}$ ) in highly densified electrodes has not been shown before and is presented in this work. Few works are simulating the 3D-thermal and 2Delectrical cell behavior of spirally wound electrodes on local scale, which is presented in this work for a $5.8 \times 61.5 \mathrm{~cm}$ electrode size and is important especially for high-energy cells as experimental findings of local hot spots [27] indicate. 


\section{Experimental methods}

The measurements in this work comprise calorimetry, infrared thermography and OCP tests of the MJ1 cell which are depicted in Table 1. In

Table 1: Measurement procedure for charge and discharge of half and full cells

\begin{tabular}{cccc}
\hline $\begin{array}{c}\text { Calorimetry measurement (full cell \#1-MJ1) } \\
\text { Step }\end{array}$ & Current rate & Termination & $\begin{array}{c}\text { Initial } \\
\text { Temperature }\end{array}$ \\
\hline CC & $\mathrm{C} / 5$ & $2.5 \mathrm{~V}-4.2 \mathrm{~V}$ & \\
CV & - & until $167.5 \mathrm{~mA}$ & $25^{\circ} \mathrm{C}$ \\
Thermal relaxation & 0 & $10 \mathrm{~h}$ &
\end{tabular}

Ambient

Thermography measurement (full cell \#2-MJ1)

$\begin{array}{cccc}\text { Preconditioning CC } & 1 \mathrm{C} & 2.5 \mathrm{~V}-4.2 \mathrm{~V} & \\ \text { Preconditioning CV } & - & \text { until } 33.5 \mathrm{~mA} & \\ \text { Thermal relaxation I } & 0 & 4 \mathrm{~h} & 20,25 \\ \text { CC } & \mathrm{C} / 5^{\mathrm{II}}, \mathrm{C} / 2,1 \mathrm{C}, 2 \mathrm{C}{ }^{\mathrm{III}} & 2.5 \mathrm{~V}-4.2 \mathrm{~V} & 30 \text { and } 40^{\circ} \mathrm{C} \\ \text { CV } & - & \text { until } 33.5 \mathrm{~mA} & \end{array}$

Thermal relaxation II $\quad-\quad 1 \mathrm{~h}$

Open-circuit potential measurement (full cell \#3-MJ1)

$\begin{array}{cccc}\text { Preconditioning CC } & \mathrm{C} / 10 & 2.5 \mathrm{~V}-4.2 \mathrm{~V} & \\ \text { Preconditioning CV } & - & \text { until } 3.35 \mathrm{~mA} & \\ \text { Relaxation } & 0 & 6 \mathrm{~h} & 25{ }^{\circ} \mathrm{C} \\ \text { CC } & \mathrm{C} / 30 & 2.5 \mathrm{~V}-4.2 \mathrm{~V} & \\ \mathrm{CV} & - & \text { until } 3.35 \mathrm{~mA} & \end{array}$

Open-circuit potential measurement for the half cells

\begin{tabular}{cccc}
\hline Soaking & 0 & $12 \mathrm{~h}$ & \\
$\mathrm{CC}$ & $\approx \mathrm{C} / 100$ & $0.010-1.7 \mathrm{~V}(\mathrm{SiC})$ & $25^{\circ} \mathrm{C}$ \\
& & $3.0 \mathrm{~V}-4.3 \mathrm{~V}(\mathrm{NMC}-811)$ & \\
\hline
\end{tabular}

I $1.0 \mathrm{C} \equiv 3.35 \mathrm{~A}[21,47] \quad$ II only at $25^{\circ} \mathrm{C} \quad$ III only discharge at $25^{\circ} \mathrm{C}$

terms of the calorimetry, the heat generation of a pristine MJ1 cell (\#1$\mathrm{MJ1}$ ) was measured at a $0.2 \mathrm{C}, 0.5 \mathrm{C}$ and $1.0 \mathrm{C}$ constant-current $(\mathrm{CC})$ charge- 
and discharge-rate with an accelerating rate calorimeter (EV-ARC, Thermal Hazard Technology) combined with a cylcer (CTS, Basytec). Each charge and discharge step was followed by a constant voltage (CV) period with a termination criterion of $0.05 \mathrm{C}$ at $4.2 \mathrm{~V}$ and $2.5 \mathrm{~V}$, respectively. After each step the cell was rested for at least $10 \mathrm{~h}$. The total heat capacity of the cell was determined during the adiabatic conditions in the calorimeter and via the thermography measurements during the period 'Thermal relaxation II' (see Table 1).

Regarding the thermography measurements [48], the temperature distribution at the surface of the cell (\#2-MJ1) and the adjacent copper connectors (1860C006, Feinmetall [49]) was measured during different charge- (0.2, 0,5 and 1.0) and discharge-rates $(0.2,0.5,1.0$ and 2.0) via an infrared camera (A655sc, FLIR Systems Inc.) with an accuracy of $\pm 2 \mathrm{~K}$ at four different ambient temperatures $\left(20,25,30\right.$ and $\left.40^{\circ} \mathrm{C}\right)$. To increase temperature accuracy, the infrared thermography temperature data is referenced to a four-wire Pt100 sensor with an absolute accuracy of $\pm 0.15 \mathrm{~K}$ at $0{ }^{\circ} \mathrm{C}(\mathrm{DIN} / \mathrm{IEC}$ Class A). The optical resolution of $80 \times 480$ pixels provides a relative accuracy of $\pm 30 \mathrm{mK}$ between the pixels. Turbulent air-flow at 1.0 and $2.0 \mathrm{~m} \mathrm{~s}^{-1}$ guaranteed convective cooling with a heat transfer coefficient of $22.4 \mathrm{~W} \mathrm{~m}^{-2} \mathrm{~K}$ and $32.1 \mathrm{~W} \mathrm{~m}^{-2} \mathrm{~K}$ (see Table A.8) in a custom-built climate chamber [48] combined with a cycler (HPS, Basytec).

OCP-measurements for charge and discharge of the anode $(\mathrm{SiC})$ and cathode (NMC-811) half cells as well as for the full cell (\#3-MJ1) were measured in a climate chamber (VT 4021, Vötsch Industrietechnik $\mathrm{GmbH}$ ) at $25^{\circ} \mathrm{C}$ combined with a cycler (CTS, Basytec). The applied current for both half cells 
was set to $80 \mu \mathrm{A}(\approx 0.01 \mathrm{C})$ and $101 \mathrm{~mA}(\approx \mathrm{C} / 30)$ for the full cell. As the electrodes of the coin cells were extracted from an already utilized cell, no formation cycles were necessary.

\subsection{Open-circuit potential measurements}

The electrodes for the half cells were extracted from full cell \#4-MJ1 at $3 \mathrm{~V}$, which was opended inside an argon-filled glove-box (M.Braun InertgasSysteme $\mathrm{GmbH})$. Single-side coated electrode samples $(\oslash 14 \mathrm{~mm})$ for the CR2032-type coin cell were gained from a single-coated area at the outer end of the anode and via mechanical abrasion using a scalpel for the continuously double-side coated cathode. The assembly included two aluminum spacers $(0.5 \mathrm{~mm} / 1 \mathrm{~mm})$, two glasfiber separators each of $250 \mu \mathrm{m}$, a single lithium-metal coin $(250 \mu \mathrm{m})$ and the remaining CR2032-type housing caps, wave spring and insulation ring.

The anode half cells were filled with $90 \mu \mathrm{L}$ of $1 \mathrm{M} \mathrm{LiPF}_{6}$ in 3:7 (wt:wt) ethylene carbonate (EC)/ethyl methyl carbonate (EMC) electrolyte $(99.9 \%$ purity, Solvionic) under ambient pressure $(\approx 1$ bar $)$ in the glove-box.

The assembled NMC-811 half cells did not function, when the electrolyte was inserted under ambient pressure. Wetting cathode samples under vacuum in a pressure chamber (Harro-Höfliger Verpackungsmaschinen GmbH) within the glove-box, the coin cells operated normally. The pressure profile shown in Table 2 was used for the wetting process. As the NMC-811 electrode is even more dense with a porosity of $17.1 \%$ than the $\mathrm{SiC}$ anode $(21.6 \%)$ (Mercury porosimetry, PASCAL 140/440 with CD3 dilatometer), capillary and wettability effects may inhibit the electrolyte from entering the pore. After this first phase of wetting, another $70 \mu \mathrm{L}$ of electrolyte are added to 
Table 2: Pressure profile for wetting NMC-811 electrodes

\begin{tabular}{lcc}
\hline Step & Pressure / mbar & Duration $/ \mathrm{s}$ \\
\hline Vaccum I & 10 & 10 \\
Release I & 60 & 10 \\
Vaccum II & 30 & 10 \\
Release II & 80 & 10 \\
Vaccum III & 30 & 10 \\
Wetting & 30 & 1 \\
\hline
\end{tabular}

the coin cell.

\subsection{Entropy measurements}

The entropy profiles of the positive and negative electrode were measured using a potentiometric method [50]. The anode and the cathode half cells were initially set to $10 \mathrm{mV}$ and $4.6 \mathrm{~V}$ respectively at $0.1 \mathrm{C}$ with a subsequent $\mathrm{CV}$ period and termination criterion of $\mathrm{C} / 1000$. Afterwards the anode was delithiated and the cathode was lithiated with $\mathrm{C} / 30$ at SoC steps of $6.25 \%$ gaining $17 \mathrm{SoC}$ points in total. After resting for $6 \mathrm{~h}$ at $25^{\circ} \mathrm{C}$, a positive temperature pulse of $10 \mathrm{~K}$ amplitude and $4 \mathrm{~h}$ duration immediately followed by a negative pulse of the same amplitude and duration was applied according to the work of Zilberman et al. [50] at each SoC step with a climate chamber (KT115, Binder), which ensured isothermal test condition at a temperature accuracy of $\pm 15 \mathrm{mK}$. PT100 sensors were used to measure the temperature at the surface of each cell. As the half cell voltage was not completely relaxed after $6 \mathrm{~h}$, the voltage response to the temperature profile was corrected using the method presented in Osswald et al. [51]. 


\section{Modeling}

In this work, the single p2D model and the MuDiMod incorporating several p2D models, the $2 \mathrm{D}$ electrical model of the current collectors and the $3 \mathrm{D}$ thermal model of the jelly roll are used. The parameterization of the MJ1 cell is explained more in detail for the high-capacity active materials and additionally, the parameterization for the 2D and 3D model are depicted in Table A.9 and Table A.10.

\subsection{Silicon-graphite anode}

The dry anode half cell samples were weighed with a total mass of $37.3 \mathrm{mg}$ (Quintix 224-1S, Sartorius Mechatronics) and with the calculated weight of the current collector $\left(\oslash 14 \mathrm{~mm} \times 11 \mu \mathrm{m}, \rho_{\text {copper }}=8.95 \mathrm{~g} \mathrm{~cm}^{-3}[52]\right)$, the weight of the dry electrode is estimated as $22.1 \mathrm{mg}$. The current collector thickness was derived from inductively coupled plasma-optical emission spectroscopy (ICP-OES, Varian 7XX-ES ICP-OES Spectrometer, Agilent Technologies), referring to the measured amount of copper and the sample size $(\oslash 20 \mathrm{~mm})$. The total thickness of the electrode was measured via laser microscopy (VK9710K Violet Laser 408nm, KEYENCE CORPORATION) and micrometer caliper (Micromar 40 EWV, Mahr $\mathrm{GmbH}$ ), resulting in a coating thickness of $86.7 \mu \mathrm{m}$. Mercury porosimetry (PASCAL 140/440 with CD3 dilatometer, PASCAL) revealed porosity values of $21.6 \%$ which leads to a total solid volume of $10.1 \mathrm{~mm}^{3}$ for the coin sample. The fraction of silicon in graphite could be determined via ICP-OES to $\approx 3.5 \mathrm{wt} \%$. Specific gravimetric capacities of natural graphite [10] and nano-particle sized silicon [53] can be estimated to $330 \mathrm{mAh}^{-1}$ and $3600 \mathrm{mAh}^{-1}$. Referring to standard com- 
positions of active and inactive material [1, 54], $9 \mathrm{wt} \%$ are assumed to consist of binder and carbon black (combined density of $\approx 1.78 \mathrm{~kg} \mathrm{~m}^{-3}[55,56]$ ), resulting in a content of graphite of $87.5 \mathrm{wt} \%$. The maximum theoretical loading $\left(b_{g}\right)$ of the anode is calculated [11] to $415 \mathrm{mAh} \mathrm{g}^{-1}$, which is well in line with comparable gravimetric loadings for $\mathrm{SiC}$ [10]. Considerung $21.6 \%$ porosity and the densities $(\rho)$ of binder, carbon black and 3.5-87.5 wt\% $\mathrm{SiC}$ $\left(2.24 \mathrm{~g} \mathrm{~cm}^{-3}\right.$, derived from Ref. [10]), the total volumetric fractions can be calculated [10] to $9 \%$ (carbon black/binder) and $69.4 \%$ (SiC) from the gravimetric composition. The maximum lithium-ion concentration in the anode is estimated to $34684 \mathrm{~mol} \mathrm{~m}^{-3}$ according to Eq. 1 .

$$
c_{\text {smax }}=b_{g} \cdot \rho \cdot F^{-1}
$$

The particle radius $\left(R_{p, \mathrm{D} 50}\right)$ was derived from the mercury porosomitry to $6.1 \mu \mathrm{m}$. Both lithiation and delithiation paths are considered to estimate the equilibrium potential $[57,58]$ in the single p2D model for charge and discharge simulation of the full cell, as the silicon doped graphite shows distinct hysteresis effects which is well in line with other works [59]. In order to match the measured capacity of the coin cells to the lithiation level, two reference points were considered at $0 \mathrm{mAh}$ and at the transition of $\mathrm{LiC}_{12}$ to $\mathrm{LiC}_{6}[60]$, which can be clearly seen in the derivative of the potential vs. capacity. Due to the hysteresis effect, the averaged value in capacity between both peaks in the lithiation and delithiation path was used to match approximately the $50 \%$ level [61]. 


\subsection{Nickel-rich cathode}

Similar to the anode half cells, the weight of the cathode samples was derived to $37.1 \mathrm{mg}$ with a thickness of $17.3 \mu \mathrm{m}$ for the aluminum current collector $\left(\rho_{\text {aluminum }}=2.71 \mathrm{~g} \mathrm{~cm}^{-3}[52]\right)$. The composition of $82 \%-6.3 \%-11.7 \%$ for nickel, manganese and cobalt was determined via ICP-OES and slightly differs from a strictly $80 \%-10 \%-10 \%$ ratio. Regarding the cathodic porosity of $17.1 \%$ and the coating thickness of $66.2 \mu \mathrm{m}$, the total solid volume accounts to $8.44 \mathrm{~mm}^{3}$ for the coin sample. A standard gravimetric composition of $96 \mathrm{wt} \%$ to $4 \mathrm{wt} \%$ [54] ratio for the active and inactive parts and a crystallographic density of $4.87 \mathrm{~g} \mathrm{~cm}^{-3}$ for NMC-811 [7] is assumed here. Considering the porosity of $17.1 \%$, the volumetric fractions are calculated [10] to $74.5 \%$ (NMC-811) and $8.4 \%$ (cabon black/binder). The specific gravimetric capacity of the NMC-811 material is assumed to be $275.5 \mathrm{mAh} \mathrm{g}^{-1}$ [7]. The particle radius $\left(R_{p, \mathrm{D} 50}\right)$ is derived as $3.8 \mu \mathrm{m}$ and thus the theoretical maximum concentration is calculated to $50060 \mathrm{~mol} \mathrm{~m}^{-3}$ (see Eq. 1).

The lithiation level during both lithiation and delithiation of the OCP is calculated via setting two points at the measured half cell capacity and at $0 \mathrm{mAh}$ in reference to $275.5 \mathrm{mAh}^{-1}$ [7]. The derived lithiation degrees are well in line with other findings [6].

The determination of the lithiation degree of both electrodes is applied similary for the entropic coefficents. The complete parameterization of the NMC$811 / \mathrm{SiC}$ porous electrodes is given in Table 3. 
Table 3: Parameterization of the single p2D model with NMC-811/SiC electrodes

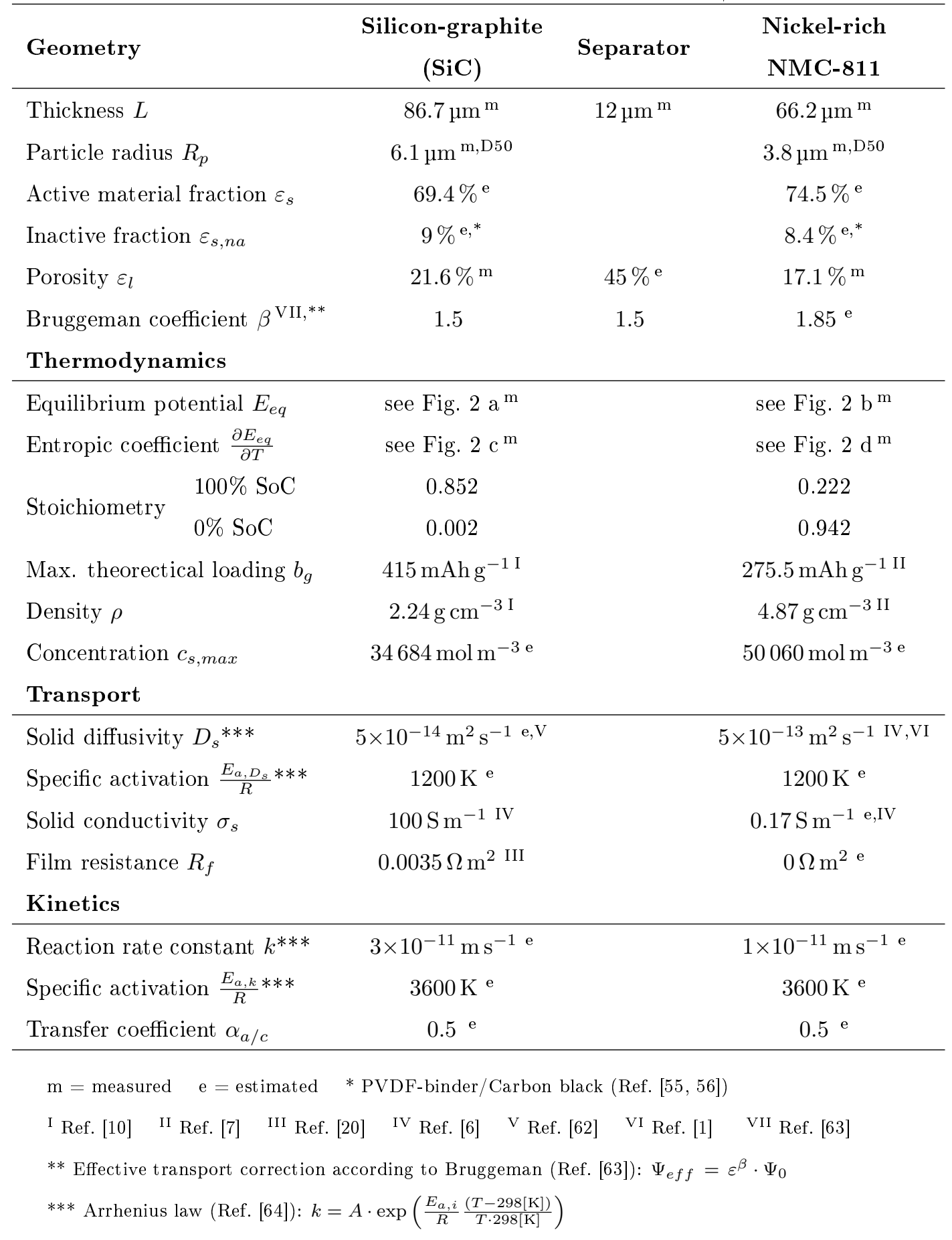


Gas-chromatography combined with mass spectroscopy (Clarus 560/600 GC/MS, PerkinElmer LAS GmbH) of the electrolyte in the MJ1 revealed contents of EC, EMC and dimethyl carbonate (DMC) and the values for a $1 \mathrm{M} \mathrm{LiPF}_{6}$ in polypropylene carbonate $(\mathrm{PC}) / \mathrm{EC} / \mathrm{DMC}$ were used as the most appropriate set available in literature from Valøen and Reimers [65] (see Table A.9). As transport correction for the liquid diffusion coefficient $\left(D_{l}\right)$, the ionic conductivity $\left(\kappa_{l}\right)$ and the electrical conductivity in the active material $\left(\sigma_{s}\right)$ [23], the Bruggeman correlation [63] was used with increased coefficients $(\approx 23 \%)$ for the cathode to account for the low porosity of $17.1 \%$. To the authors' knowledge, this is the first effort to parameterize a newmantype p2D model for a NMC-811/SiC lithium-ion cell.

\subsection{Single p2D and Multi-Dimensional Model}

The electrochemical model used in this work is the widely applied newmantype p2D model [22] which is based on porous electrode theory, reaction kinetics and concentrated solution theory [66]. The model equations are summarized in Table A.12 in the appendix.

For the single p2D model, an additional thermal model calculates the volumeaveraged cell temperature from heat generation due to ohmic losses in the solid and liquid phase $\left(q_{s}, q_{l}\right)$, reaction overpotential $\left(q_{r}\right)$, entropy change $\left(q_{r e v}\right)$ and contact resistance $\left(q_{e x t}\right)$. Heat transfer to the environment is considered via convection $\left(q_{\text {conv }}\right)$ and radiation $\left(q_{r a d}\right)$. In case of the thermography measurements, heat conduction via the connectors is also described $\left(q_{c o n}\right)$. The reference temperature $\left(T_{c o n}\right)$ for the heat conduction was measured on the surface of the connectors.

The MuDiMod consists of several p2D models calculating electrochemical 
potentials and lithium-ion concentrations perpendicular to the current collectors, the $2 \mathrm{D}$ model accounting for the electrical potential along the current collectors and the 3D model calculating the local temperature within the jelly roll of the cylindrical cell. As the basic MuDiMod is already published in previous works $[24,25]$ with an extension of using effective spatial discretization techniques [26], only novel implemented techniques or submodels are outlined here.

An additional charge balance (see Table A.12) guarantees the charge transfer from the p2D models to be in agreement to the total current applied at the cell's tabs in the $2 \mathrm{D}$ model in order to avoid slight deviances in the SoC calculation.

Moreover, a fully spatially resolved 3D thermal model for cylindrical cells is incorporated which enables for local coupling of heat generation calculated in the p2D and 2D models and temperature distribution along the electrodes instead of using lumped thermal models [23]. The local coupling enables for analyzing tab pattern influences on heat generation, temperature distribution and local differences in SoC [32].

In general, a computationally efficient mathematical description of the coordinate transformation between a spirally wound domain and its unwound representation is needed for a lean exchange of local states between the related submodels. A variable extrusion algorithm proofed to enable a coupling of a planar 2D and spirally wound 3D model whilst using only $35 \%$ of RAM and saving $97 \%$ of computation time with sufficient accuracy compared to fully-discretized models [42]. Based on this approach, an extended coupling algorithm transfers the local heat generation of the p2D and the 2D model 
forward to the $3 \mathrm{D}$ thermal model via coordinate mapping, incorporating a lumped finite element methode (FEM) discretization-mesh in the 3D model. By implication, the local temperature is transferred backwards to the $2 \mathrm{D}$ model and the p2D models. Further explanation would exceed the scope of this work, therefore the necessary mapping procedure is explained explicitly in the supplementary material of this work beside the chosen FEM-mesh for the p2D and the MuDiMod implemented in COMSOL Multiphysics 5.3a. As the positive $(+)$ and negative $(-)$ current collector tab in the MJ1 cell are located in the center and at the outer end of the jelly roll, electrode utilization is investigated via different tab design to evaluate the electrical configuration on the current collector foils. In this work, the positive/negative tabs are exclusively located at the top/bottom of the electrode. Using several counter-position tabs in different patterns was seen to increase the usable energy density [44] during charge of the cell and following this, possible optimization of the electrical configuration is investigated via three alternative tab patterns (i.e 1x1, 1x2 and $2 \times 3$ ), which are depicted in Table 4 . The

Table 4: Different tab designs for the 18650 NMC-811/SiC cell

\begin{tabular}{ccccc}
\hline Tab pattern & \multicolumn{2}{c}{$\begin{array}{c}\text { Number of tabs } \\
+^{*}\end{array}$} & $\begin{array}{c}\text { Position of tabs } \\
\text { along the electrode }\left(x^{\prime} / \mathrm{cm}\right) \\
-* *\end{array}$ & - \\
\hline MJ1 & 1 & 1 & 0 & 61.5 \\
(INR18650-MJ1 reference) & & & & $\frac{61.5}{2}$ \\
$\mathbf{1 x 1}$ & 1 & 1 & $\frac{61.5}{2}$ & $0 ; 61.5$ \\
$\mathbf{1 x 2}$ & 1 & 2 & $\frac{61.5}{2}$ & $0 ; \frac{61.5}{2} ; 61.5$ \\
$\mathbf{2 x 3}$ & 2 & 3 & $\frac{61.5}{3} ; \frac{2}{3} 61.5$ & \\
\hline
\end{tabular}

* located at $y^{\prime}=5.8 \mathrm{~cm} \quad * *$ located at $y^{\prime}=0 \mathrm{~cm}$

MuDiMod is used in this work to evaluate the original tab design of the MJ1 
cell with the alternative tab pattern during high-rate CC- and improved fast charging protocols in terms of the gained $\mathrm{SoC}$ level and the achievable energy density, tendency of lithium plating and local hot spots near the tabs.

Using the single p2D model $[67,68,69]$, lithium plating can be indicated when the potential drop $\left(\Phi_{s}-\Phi_{l}\right)$ at the particle surface and the anodeseparator interface $\left(x=L_{\text {neg }}\right)$ falls below $0 \mathrm{~V}$ without implementing actual plating kinetics. In this work, an advanced indicator state is calculated over time:

$$
\int_{t} \Phi_{s}-\Phi_{l} d t \quad \text { if } \quad \Phi_{s}-\Phi_{l}<0 \mathrm{~V} \quad \text { at } \quad x=L_{n e g}
$$

In terms of the MuDiMod, it can be used to evaluate the likeliness of lithium plating on local scale near and far from the current collector tabs considering the whole charging scenario instead of evaluating on a single time step. To estimate the amount of charge which is probably affected by lithium plating, a surface integral in the 2D electrical submodel is calculated for the transfer current density $\left(i_{p 2 D}\right)$ on the electrode area.

$$
\int_{x^{\prime}} \int_{y^{\prime}} i_{p 2 D} d y^{\prime} d x^{\prime} \quad \text { if } \quad \Phi_{s}-\Phi_{l}<0 \mathrm{~V} \quad \text { at } \quad x=L_{n e g}
$$




\section{Results and discussion}

\subsection{Differential voltage analysis}

The discharge capacities gained from the coin cells sum up to $7.96 \mathrm{mAh}$

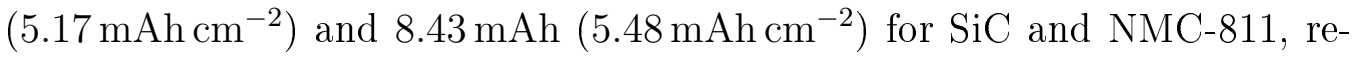
spectively. The discharge capacity of the full cell $\left(Q_{0}\right)$ was measured to $3.560 \mathrm{Ah}$ at $\mathrm{C} / 30$. The measured OCP data from the half and full cells are used for differential voltage analysis (DVA), which is shown for the charge scenario of the full cell in Fig. 1. The reconstructed OCP ('NMC811+SiC') in Fig. $1 \mathrm{a}$ is derived via extending and shifting [70] the measured half cell OCPs towards the full cell capacity level. The residual deviance is shown in Fig. $1 \mathrm{~b}$, which reveals potential errors of less than $15 \mathrm{mV}$ with an average error of $5.7 \mathrm{mV}$. For the differential potential and differential capacity shown in Fig. $1 \mathrm{c}$ and d, a capacity normalization by multiplying the differential potentials with $Q_{0}$ is performed [71]. With the aid of the differential potential, the balancing of the full cell revealed an oversized cathode $(\approx 9.4 \%)$ and an almost complete use of the anode $(>99 \%)$ referring to the specified voltage ranges (see Table 1). The potential differential (see Fig. 1 b) showed slight

deviances with a mean deviation of $230 \mathrm{mV} \mathrm{Ah}^{-1}$. The differential capacity vs. cell voltage for charge in Fig. $3 \mathrm{~d}$ matches the full cell behavior with marginal deviances. Four characteristic redox peaks can be observed at 3.42, 3.63, 3.91 and $4.1 \mathrm{~V}$ attributed to the NMC-811 cathode, which were seen similary in other works [6].

The DVA analysis for the charge scenario revealed accurate reconstruction of the full cell OCP behavior via the custom-built coin cells. Similar results were gained for the discharge scenario, which is not shown here. 

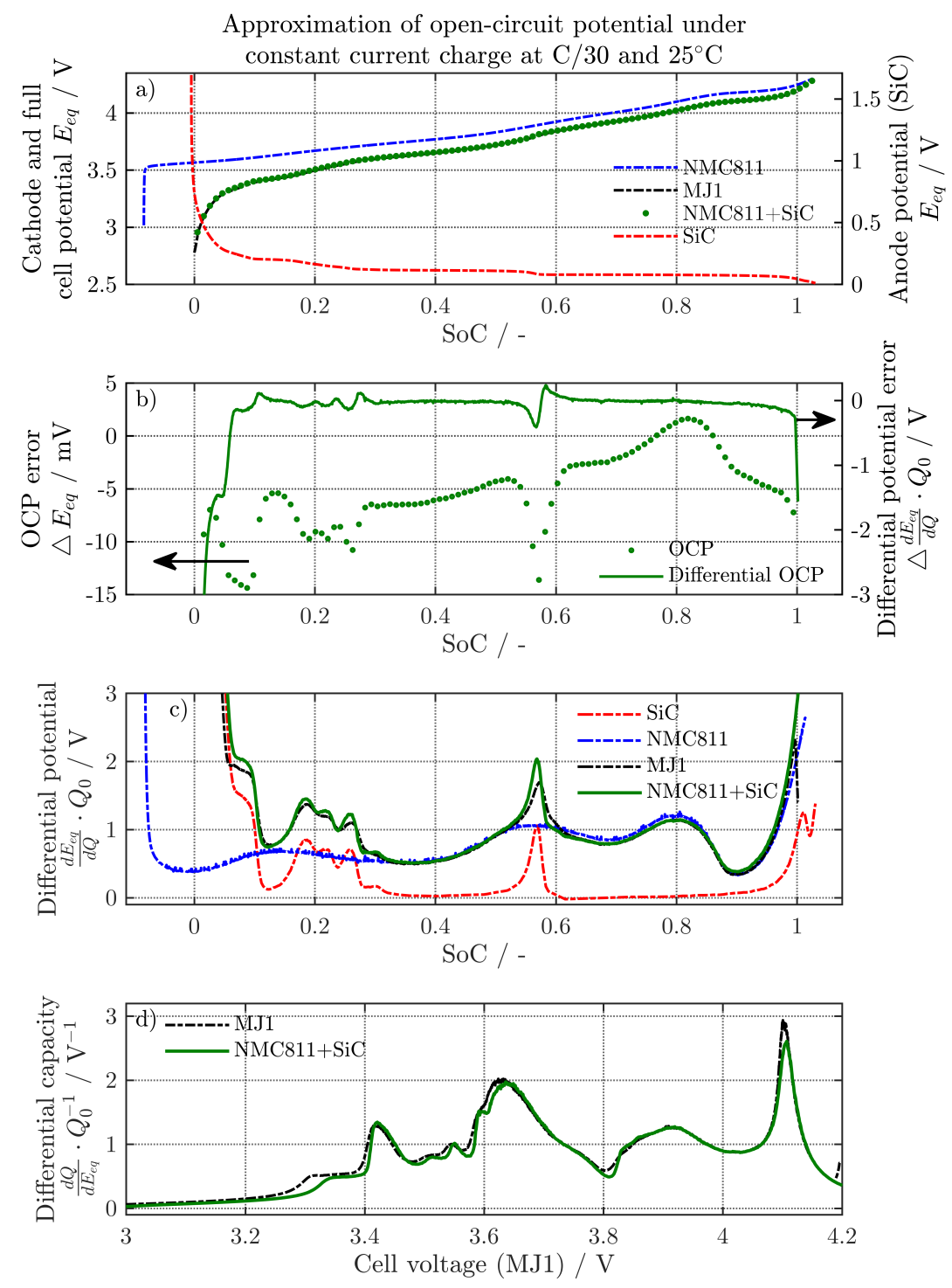

Figure 1: DVA analysis (c) was used to reconstruct the measured OCP vs. SoC (a) under charge of full cell \#3-MJ1 (see 'MJ1') via the delithiation and lithiation path of the respective coin cell (see 'NMC811' and ' $\mathrm{SiC}$ '). The approximation errors vs. SoC are shown in subplot b) and the differential capacity vs. full cell voltage together with the reconstruction (see 'NMC811+SiC') is depicted in subplot d). 


\subsection{Half cell potentials and entropic coefficients}

Derived from OCP and entropy measurements, the model parameterization is completed via the equilibrium potentials and entropic coefficents shown in Fig. 2 a to d. Regarding the full cell voltage range from 2.5 to 4.2 $\mathrm{V}$ (blue-tagged area) in Fig. $2 \mathrm{a}$ and b, the oversized cathode is evident. The initial stoichiometric coefficients are derived from the DVA analysis (see Table 3). The entropic coefficient for $\mathrm{SiC}$ in Fig. $2 \mathrm{c}$ is well in line with other measured graphite-type anodes [12, 20, 60, 72, 73, 74]. Taking these references into account, Fig. 2 e shows the range of the entropic coefficient vs. lithiation degree in the grey-tagged area together with the measured entropic profile of this work. At low lithiation levels $(<20 \%)$, graphite-type anodes show larger deviances in literature [73, 75, 76]. The fuzziness of the measured entropic coefficient below the $20 \%$ threshold resulted in larger simulation errors for the cell temperature compared to the measurements especially at the beginning of charging. As a consequence, the anode entropic coefficient was adjusted which is still well in line with results from literature as shown in Fig. 2 e.

The entropic coefficent of NMC-811 is shown in Fig. $2 \mathrm{~d}$ and resembles NMCtype active materials $[72,73,75,77]$ such as NMC-111. Referring to these works, Fig. $2 \mathrm{f}$ shows the range of the entropic coefficient for the standard NMC-type active materials in the grey-tagged area. As seen, the entropic coefficient for NMC-811 slightly exceeds this range for low lithiation degrees. Comparing both entropic coefficients, the entropic heat of the full cell is mainly depending on the anode. 

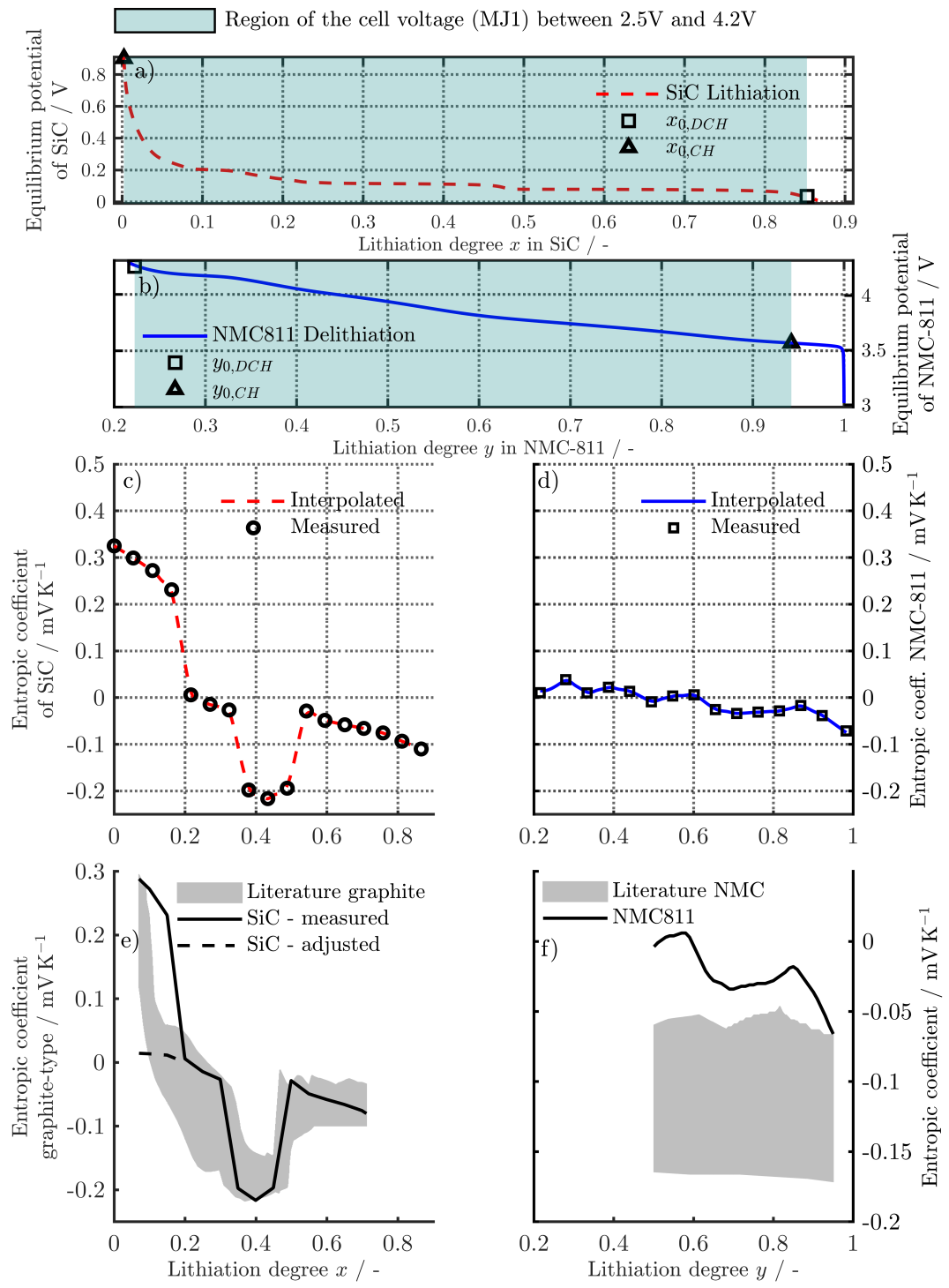

Figure 2: OCP of the SiC lithiation (a) and NMC-811 delithiation (b) path vs. estimated lithiation degree for the $\mathrm{p} 2 \mathrm{D}$ model parameterization with illustration of the full cell voltage range from $2.5 \mathrm{~V}$ to $4.2 \mathrm{~V}$ and the initial stoichiometric coefficients $\left(x_{0, i}, y_{0, i}\right)$. The measured entropic coefficient vs. estimated lithiation degree referring to the current direction of the full cell is shown for SiC (c) and NMC-811 (d) in comparison to graphite $[12,20,60,72,73,74]$ (e) and NMC [72, 73, 75, 77] (f) references from literature. 
The presented measured data in Fig 2 a to $d$ is implemented in the models via piece-wise cubic interpolation.

At this point, the parameterization of the electrochemical model is completed and in the following, the validation of the single p2D and the MuDiMod is presented via the infrared thermography and the calorimetry measurements.

\subsection{Validation via calorimetry}

The calorimetry measurements at $\mathrm{C} / 5$ discharge and charge are used to validate the simulated cell voltage, heat generation rate and temperature with focus on describing properly the thermal behavior of the cell. Using the calculated heat capacity of $42.1 \mathrm{~J} \mathrm{~K}^{-1}$ of the full cell (see section 2), the simulation results from the single p2D and the MuDiMod are shown in Fig. 3 for discharge and charge at $\mathrm{C} / 5$. The heat dip in Fig. $3 \mathrm{~b}(\approx 50 \%$ DoD $)$ can be explained by the negative entropic heat of the $\mathrm{SiC}$ active material. The overall cell behavior is predicted quite accurate by the single p2D and the MuDiMod simulation with an average error of $13.4 / 11.9 \mathrm{mV}$ and $10.5 / 16.2 \mathrm{mV}$ for the cell voltage under discharge/charge, respectively. The average temperature errors under discharge/charge resemble the measured temperature with $0.3 / 0.1 \mathrm{~K}$ and $0.8 / 0.5 \mathrm{~K}$ for the single $\mathrm{p} 2 \mathrm{D}$ and the MuDiMod. In terms of the $\mathrm{C} / 5$ charge simulation, both models show the aforementioned fuzziness of the measured entropic coefficient at low cell SoC levels (see Fig. 2 e), but the calculated temperature is nevertheless well in line with the measurement with an acceptable deviation below $1 \mathrm{~K}$ on average.

The charge and discharge simulation of the calorimetry measurements show an accurate description of the measured electrical and thermal behaviour of the MJ1 cell and a proper validation especially for the calculated heat and 

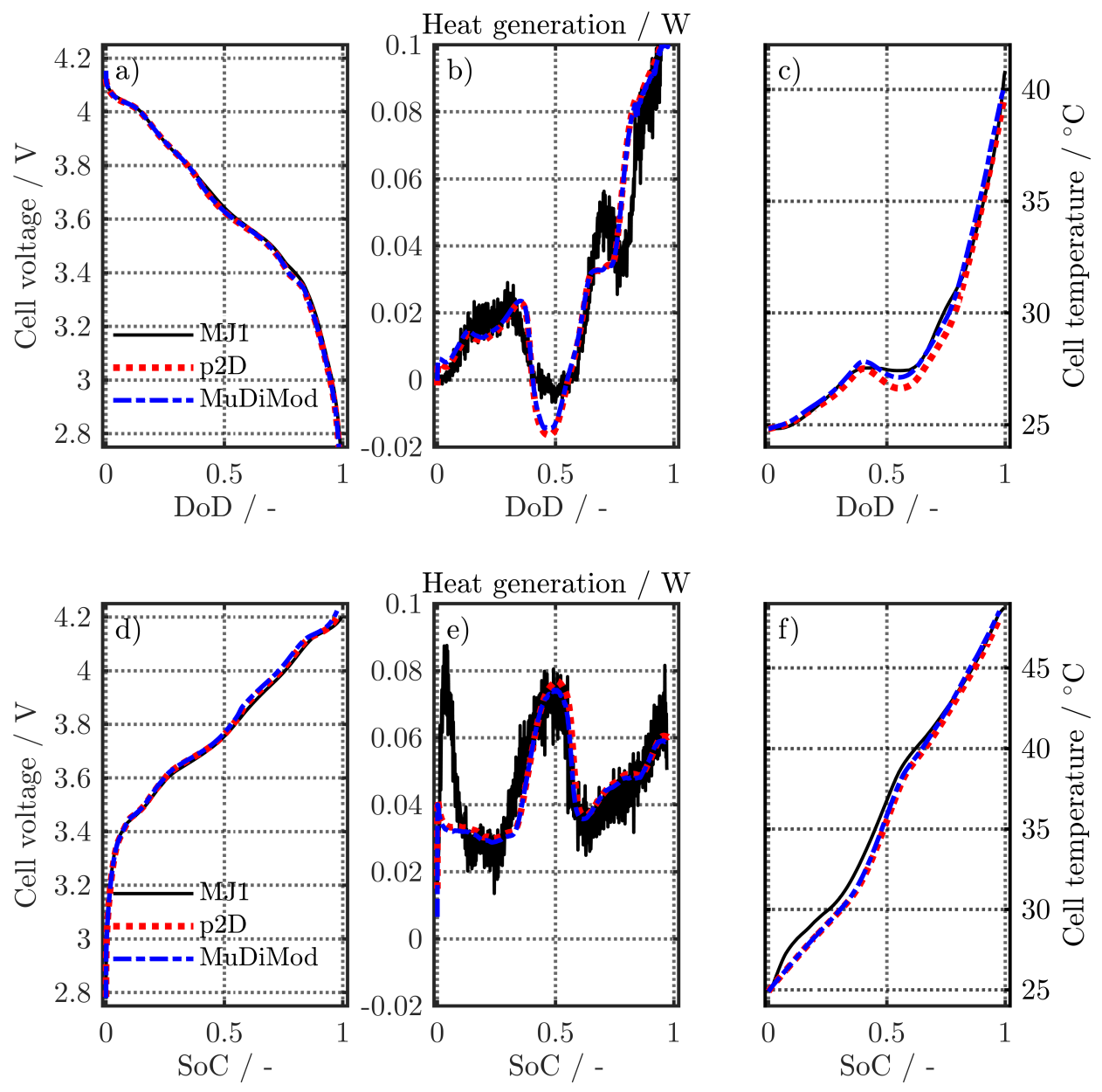

Figure 3: Calorimetry of the MJ1 cell at C/5 discharge (a, b and c) and charge (d, e and f) to validate the simulated ('p2D' and 'MuDiMod') cell voltage, heat generation rate and surface cell temperature.

temperature in the 0D- (single p2D) and 3D-thermal model (MuDiMod) was shown. 


\subsection{Validation via infrared thermography}

Thermography measurements of the full cell are used to validate the simulated cell behavior of both models in terms of varying constant charge- and discharge-rates under varying ambient temperatures and convective cooling conditions [48]. The experimental and simulated cell voltages at $25^{\circ} \mathrm{C}$ as well as the residual error are shown in Fig. 4. Following the data sheet [21], a $0.5 \mathrm{C}$ charging rate is adviced for the MJ1 while the maximum C-rate during charge is set to $1 \mathrm{C}$. Higher C-rates such as $2 \mathrm{C}$ were only applied for discharge. As shown in Fig. 4, the simulated data (a, c and e) matches to the measured cell voltage quite well during charging and at $1 \mathrm{C}$, an average error of $14.5 \mathrm{mV}$ and $13.7 \mathrm{mV}$ and a mean squared error (MSE) of $\approx 0.4(\mathrm{mV})^{2}$ is seen for the single p2D model and the MuDiMod. The largest error during charge (see Fig. 4 b, d and f) can be observed at the beginning due to the steep voltage increase referring to the anode OCP at low lithiation degrees (see Fig. $1 \mathrm{c}$ ). Similary, the maximum error appears at the end of the discharge. The simulated cell voltages at discharge in Fig. 4 match the measured data quite well and at $1 \mathrm{C}$, an average error of $13.5 \mathrm{mV}$ and $15.2 \mathrm{mV}$ and a MSE of $0.3(\mathrm{mV})^{2}$ and $0.5(\mathrm{mV})^{2}$ appear for the single $\mathrm{p} 2 \mathrm{D}$ and the MuDiMod. Only marginal differences between the single p2D and the MuDiMod can be observed except for $2 \mathrm{C}$, where approximately $20 \%$ reduced errors for the mean cell voltage are seen in the MuDiMod simulation results. Regarding the MuDiMod simulation results, current distribution on the current collectors vary $\pm 5 \%$ around the mean value of $9.4 \mathrm{~mA} \mathrm{~cm}^{-2}$, which cannot be described by a single p2D model assuming homogeneous electrode utilization, resulting in the appearing deviance between the two models. 
Constant current charging $(\mathrm{CH})$ and discharging $(\mathrm{DCH})$
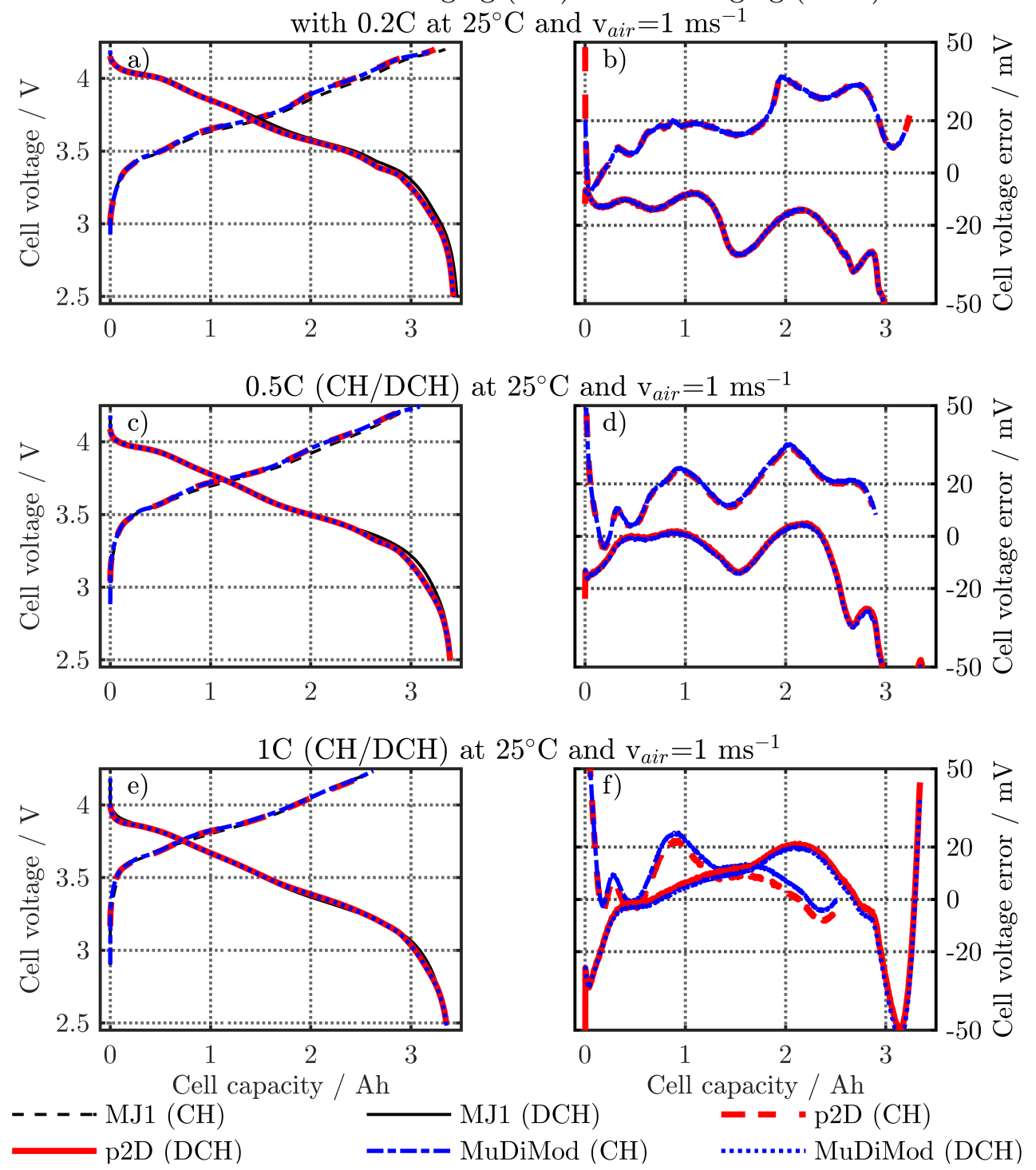

Figure 4: Thermography measurements of the MJ1 cell to validate the simulated cell voltage (a, c, and e) with the related simulation error (b, d, and f) vs. the usable cell capacity for the p2D model and the MuDiMod. 
In terms of the cell voltage, accurate simulation results appeared for both models and the temperature calculation is validated in Fig. 5 at different ambient temperatures for the single p2D model. During charge at $25^{\circ} \mathrm{C}$ (see Fig. 5 a), maximum temperature errors of $0.4 \mathrm{~K}$ and $0.6 \mathrm{~K}$ with a mean deviance of $0.1 \mathrm{~K}$ and $0.2 \mathrm{~K}$ appear at $0.2 \mathrm{C}$ and $0.5 \mathrm{C}$ respectively. At $1 \mathrm{C}$, the maximum and mean error account for $1.2 \mathrm{~K}$ and $0.34 \mathrm{~K}$, still revealing sufficient accurate simulation results. The highest deviations during discharge shown in Fig. $5 \mathrm{~b}$ appear at $2 \mathrm{C}$ with $1.4 \mathrm{~K}$ and $0.27 \mathrm{~K}$ for the maximum and mean error. Regarding the temperature profiles in the ambient temperature range from $20^{\circ} \mathrm{C}$ up to $40^{\circ} \mathrm{C}$ in Fig. $5 \mathrm{c}$ and $\mathrm{f}$, the simulated temperatures at $1.0 \mathrm{C}$ reveal an accurate prediction of the cell behavior with deviances in the range of $\pm 1 \mathrm{~K}$ (see Fig. $5 \mathrm{~d}$ and $\mathrm{f}$ ). The detailed error analysis of the thermography validation at $1 \mathrm{~m} \mathrm{~s}^{-1}$ and $2 \mathrm{~m} \mathrm{~s}^{-1}$ for the single $\mathrm{p} 2 \mathrm{D}$ model and the MuDiMod are given in the supplementary part of this work.

The thermography valdiation under both convective cooling conditions show accurate simulation of the temperature for charge and discharge and reveal errors, which are below $0.5 \mathrm{~K}$ on average and thus are in the range of the measurement accuracy.

So far, the parameterization and validation of the single p2D model and MuDiMod were shown for a high-energy NMC-811/SiC 18650 cell. Previous works $[23,51]$ already proofed the validity of the MuDiMod on a similar 26650 cell via local potential measurements along an electrode size of $5.6 \times 169 \mathrm{~cm}$ with four tabs on both the positive and the negative current collector. 

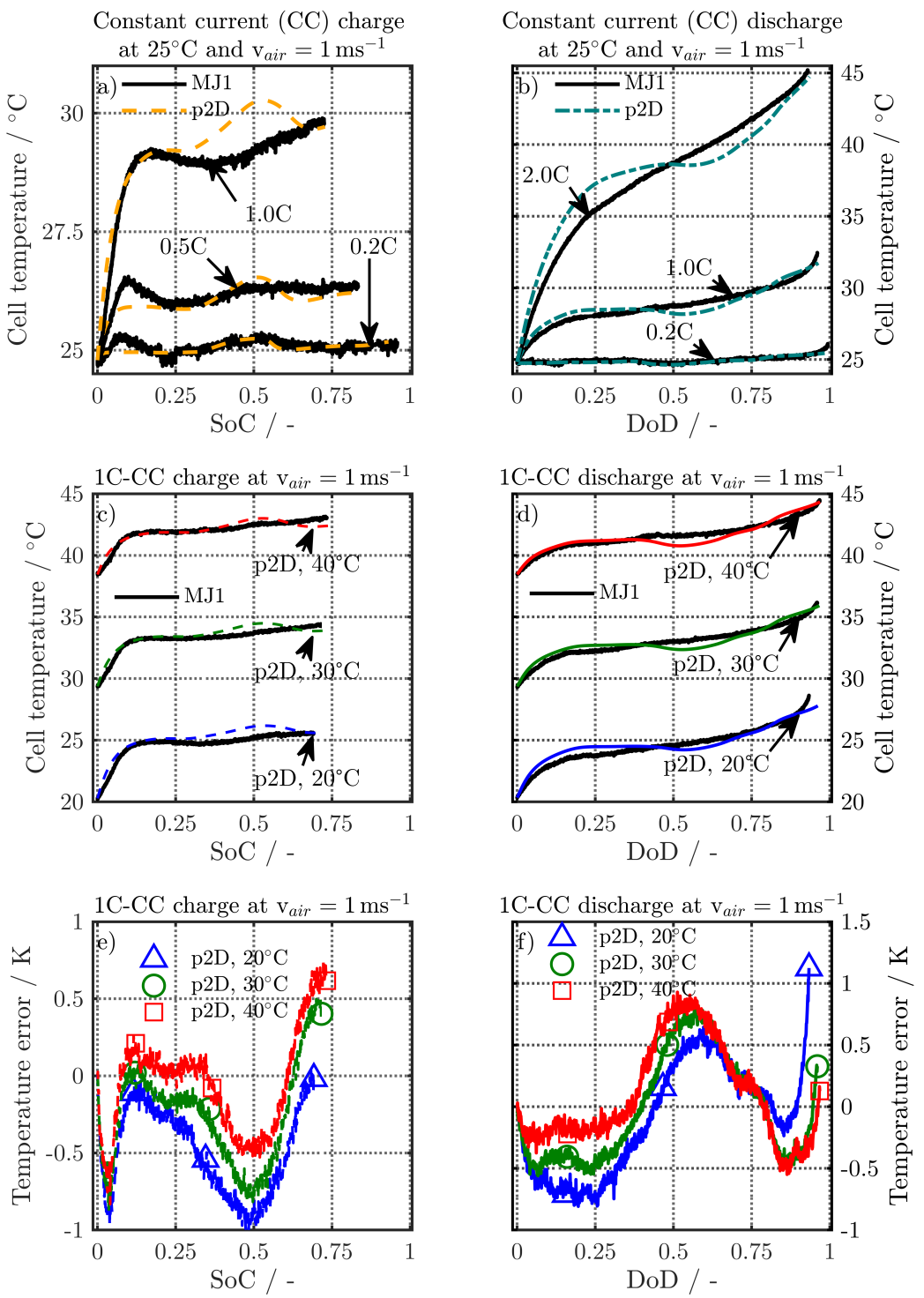

Figure 5: Thermography measurements of the MJ1 cell to validate the simulated cell temperature at different C-rates for charge (a) and discharge (b) at $25^{\circ} \mathrm{C}$ in terms of the single p2D model. 1C-CC charge (c) and discharge (d) validation at different ambient temperatures $\left(20^{\circ} \mathrm{C}, 30^{\circ} \mathrm{C}\right.$ and $\left.40^{\circ} \mathrm{C}\right)$ are shown for the single $\mathrm{p} 2 \mathrm{D}$ simulation results together with the related error (e and $\mathrm{f}$ ). 
Even if the MJ1 cell reveals a single-tab design and a local evaluation of the electrode potentials is not applicable, compared to the LFP/graphite 26650 cell the slopes of the NMC-811/SiC OCPs are higher and thus the potential and current distribution on the electrode area less critical to simulate. The following simulation studies aim for evaluating the charge-rate capability and susceptibility of lithium plating of the NMC-811/SiC active material compared to standard NMC-111/graphite [23] (see Table A.11) active material at varying electrode porosities.

\subsection{Charge characteristics of $N M C-811 / S i C$ and $N M C-111 / C$}

Referring to common NMC-111/C materials [24], electrodes with highcapacity NMC-811/SiC active materials are investigated via the single p2D model towards the influence of morphology and specific capacity on the charge-rate capability and likeliness of lithium plating during CC-charging $(1 \mathrm{C}$ to $5 \mathrm{C})$ with no additional constant voltage phase. Note, as the maximum charge-rate of the MJ1 cell is limited to $1 \mathrm{C}$, no experimental data can be shown beyond $1 \mathrm{C}$. The influence of morphology is analyzed via modeling three different porosities (i.e. high, standard (std) and low) and an overview of the simulated cell configurations is shown in Table 5. The simulation results are shown in Fig. 6 in terms of the gained SoC level at the end-of-charge (EoC) (a) referring to the relative discharge capacity $(3.35 \mathrm{Ah})$, the potential drop $\left(\Phi_{s}-\Phi_{l}\right)$ at the anode-separator interface (b) and its cumulative time-integral (c, see also Eq. 2). Regarding Fig. 6 a, the expectable decrease of the gained SoC with increasing C-rate and decreasing porosity is well in line with other works [79]. Charge-rate limitation appears beyond 3C for both NMC-111/C and NMC-811/SiC due to mass transport narrowing for 
Table 5: Different porous electrodes with NMC-111/C and NMC-811/SiC ref. to $1 \mathrm{C}$

\begin{tabular}{llcccccc}
\hline & & \multicolumn{3}{c}{ NMC-111/C* } & \multicolumn{3}{c}{ NMC-811/SiC } \\
\hline Tag & & high & std & low & high & std & low \\
Porosity & $\%$ & $45 / 50$ & $35 / 35$ & $17.1 / 21.6$ & $45 / 50$ & $35 / 35$ & $17.1 / 21.6$ \\
Capacity & $\mathrm{Ah}$ & 1.54 & 1.95 & 2.67 & 2 & 2.71 & 3.35 \\
Specific capacity & $\mathrm{mAh} \mathrm{cm}^{-2}$ & 2.2 & 2.7 & 3.7 & 2.8 & 3.8 & 4.7 \\
\multirow{2}{*}{ Specific energy density } & $\mathrm{Wh} \mathrm{kg}^{-1} \mathrm{I}$ & 122 & 155 & 211 & 159 & 214 & 275 \\
& $\mathrm{Wh} \mathrm{l}^{-1 \mathrm{II}}$ & 339 & 428 & 586 & 440 & 593 & 713 \\
\hline
\end{tabular}

* P2D parameterization according to Ref. [24, 78, 73] (see A.11)

I Ref. to cell weight of $45.8 \mathrm{~g}$ (MJ1)

II Ref. exemplarily to a 18650 volume of $16.5 \mathrm{~cm}^{3}$ and nominal voltage of $3.635 \mathrm{~V}$ [21] (MJ1)

lithium-ions in the electrolyte with appearing depletion of the pore, which limits the capability of charge transfer and leads to a premature approach of the cut-off voltage. Regarding the indication of lithium plating in Fig. 6 b, no plating is indicated at 3C except for the NMC-111/C-low simulation results. Analyzing the reaction kinetics during $3 \mathrm{C}$ of the $\mathrm{NMC}-811 / \mathrm{SiC}-\mathrm{low}$ and the NMC-111/C-low configuration, reveals larger overpotentials $(\approx 36 \%)$ due to a lower exchange current density $(\approx 40 \%)$ on average for the NMC-111/C cell which cause the negative potential drop. The lower exchange current density of the NMC-111/C compared to the NMC-811/SiC cells is caused by the lower maximum concentration $(\approx 10 \%)$ and the lower heat generation $(\approx 25 \%)$ and calculated temperature $(\approx 13 \%)$ resulting in lower reaction kinetics. In the same way lower potential drops are caused for $4 \mathrm{C}$ and $5 \mathrm{C}$ for the NMC-111/C cells. In this matter, differences in reaction kinetics between natural and silicon-doped graphite were already seen [13] and experimental analysis on the reaction rates of high-capacity and standard NMC-type active materials could further clarify the findings of this work.

Using the indication state given in Eq. 2 of this work, the tendency of lithium plating can be estimated as shown in Fig. $6 \mathrm{c}$ referring to the whole charge 

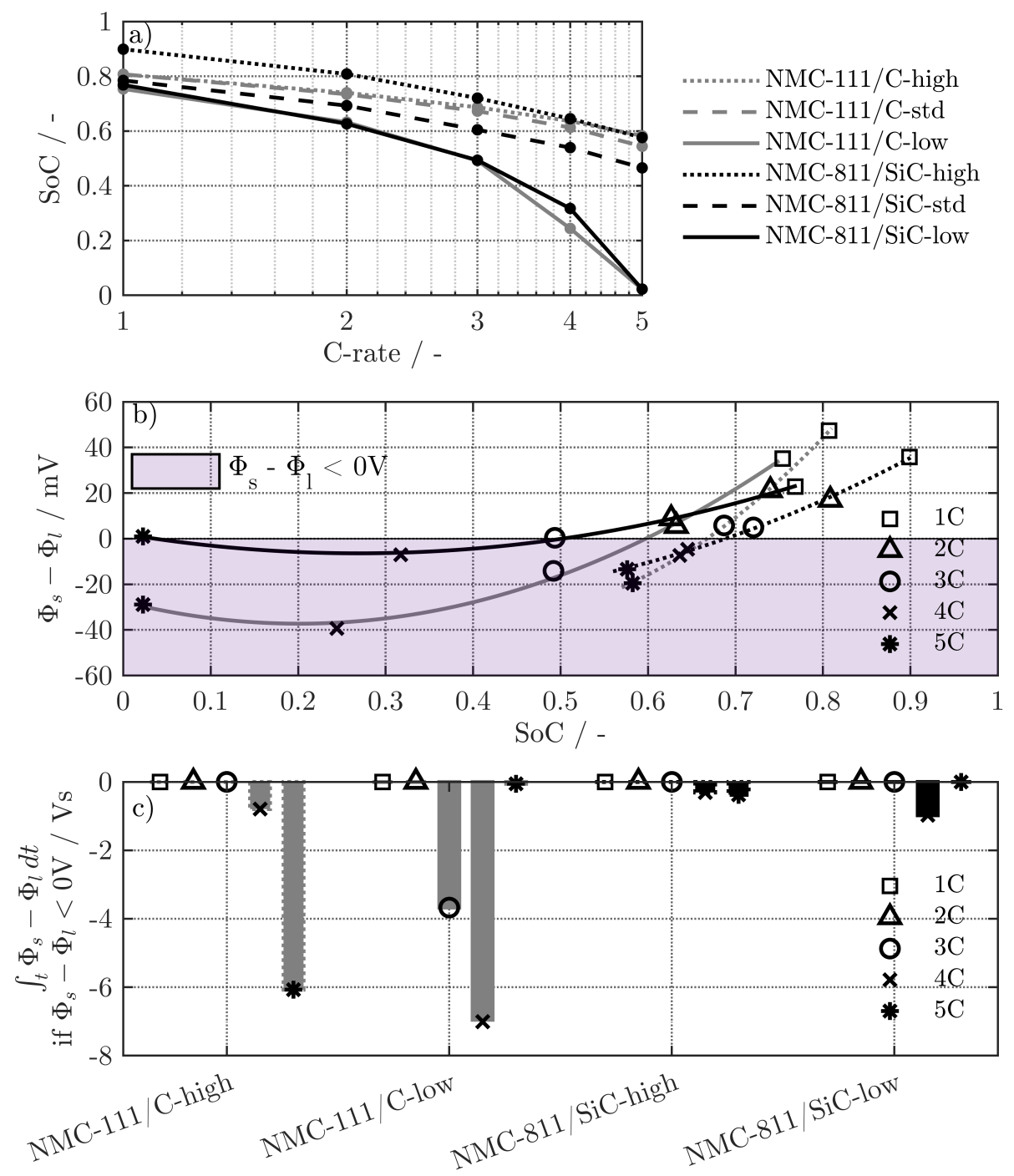

Figure 6: Single p2D CC-charging simulation results of NMC-111/C and NMC-811/SiC lithium-ion cells with different electrode porosities (high/std/low) from $1 \mathrm{C}$ to $5 \mathrm{C}$. The SoC referring to the usable discharge capacity ( $3.35 \mathrm{Ah}$ ) is shown over the applied C-rate in a) and the likelihood of lithium plating is evaluated locally in b) and over time in c). 
process instead of evaluating a single time step as in Fig. 6 b. Gaining approximately the same cell $\mathrm{SoC}$ level at $4 \mathrm{C}$, lithium plating is indicated two times more for NMC-111/C compared to NMC-811/SiC for high porous electrodes. Regarding $5 \mathrm{C}$, the ratio increases up to a factor of 16 . For low porous electrodes, similar characteristics are seen with even higher indication values of up to $-7 \mathrm{Vs}$ for the NMC-111/C-low cell. At $5 \mathrm{C}$, the cut-off voltage is reached at cell SoC levels below $3 \%$ and the charge process ends before the onset of lithium plating. In sum, the NMC-811/SiC type cells reveal less onset of lithium plating ( $>-1 \mathrm{Vs}$ ) compared to NMC-111/C.

As the single p2D model assumes homogeneous electrode utilization along the electrodes, no lateral electrode effects can be considered, which are induced via the total number [43], position [44] and the geometry of the tabs [39] or the overall thickness of the current collector foils [46, 80]. To evaluate lateral electrode effects, the original tab design of the MJ1 cell and three alternative tab patterns are investigated at high-rate $\mathrm{CC}$ - and modified fast charging protocols with the MuDiMod. 


\subsection{Relation between tab design and non-homogeneous electrode utilization}

High-rate CC-charging from $1 \mathrm{C}$ to $4 \mathrm{C}$ is simulated from 2.5 to $4.2 \mathrm{~V}$ with the MuDiMod regarding the four different tab designs (see Table 4). The tendency of lithium plating along the electrode is shown at $3 \mathrm{C}$ in Fig. 7 according to Eq. 2 together with three reference points, which describe charactersitic maxima (i.e. near the tabs - P1, P2) and minima (i.e. far from the tabs - P3) of local electrode polarization. The MJ1 tab pattern (Fig. 7 a and b) reveals the smallest cell SoC level (41.1\%) at EoC due to the longest effective current pathways and related ohmic losses, showing no indication towards lithium plating. In contrast, the remaining configurations (see Fig. 7 $\mathrm{c}$ to $\mathrm{h}$ ) yield to higher SoC levels $(52.5 \%, 53 \%$ and $58.1 \%)$ at the cost of possible lithium plating, which starts at $43.6 \%, 34.8 \%$ and $31.6 \%$ SoC along the entire electrode (i.e. $\mathrm{P} 3<0 \mathrm{~V}$ ) for the $1 \mathrm{x} 1,1 \times 2$ and $2 \mathrm{x} 3$ tab pattern, respectively. Looking at the tab-near regions (P1 and P2) in Fig. $7 \mathrm{~d}$, $\mathrm{f}$ and

$\mathrm{h}$, the onset of lithium plating appears even earlier at a cell $\mathrm{SoC}$ of $23.6 \%$, $28.7 \%$ and $28.1 \%$, respectively. Fig. 7 c, e and $g$ illustrate the local onset near the tabs and the penetration depth of the regions far from the tabs for the likelihood of lithium plating. The $2 \times 3$ pattern shows the highest risk with an average value of $-4.2 \mathrm{Vs}$ compared to $-1.93 \mathrm{Vs}$ and $-1.95 \mathrm{Vs}$ for the $1 \mathrm{x} 2$ and $1 \mathrm{x} 1$ configuration. Regarding the temperature distribution on the electrodes at EoC, the maximum spread appears for the MJ1 pattern with $59.7{ }^{\circ} \mathrm{C}$ and $67.5^{\circ} \mathrm{C}$ at the outer end and the positive tab in the center of the jelly roll, which is well in line with experimental results for high-energy 18650 cells during fast charging [27]. 

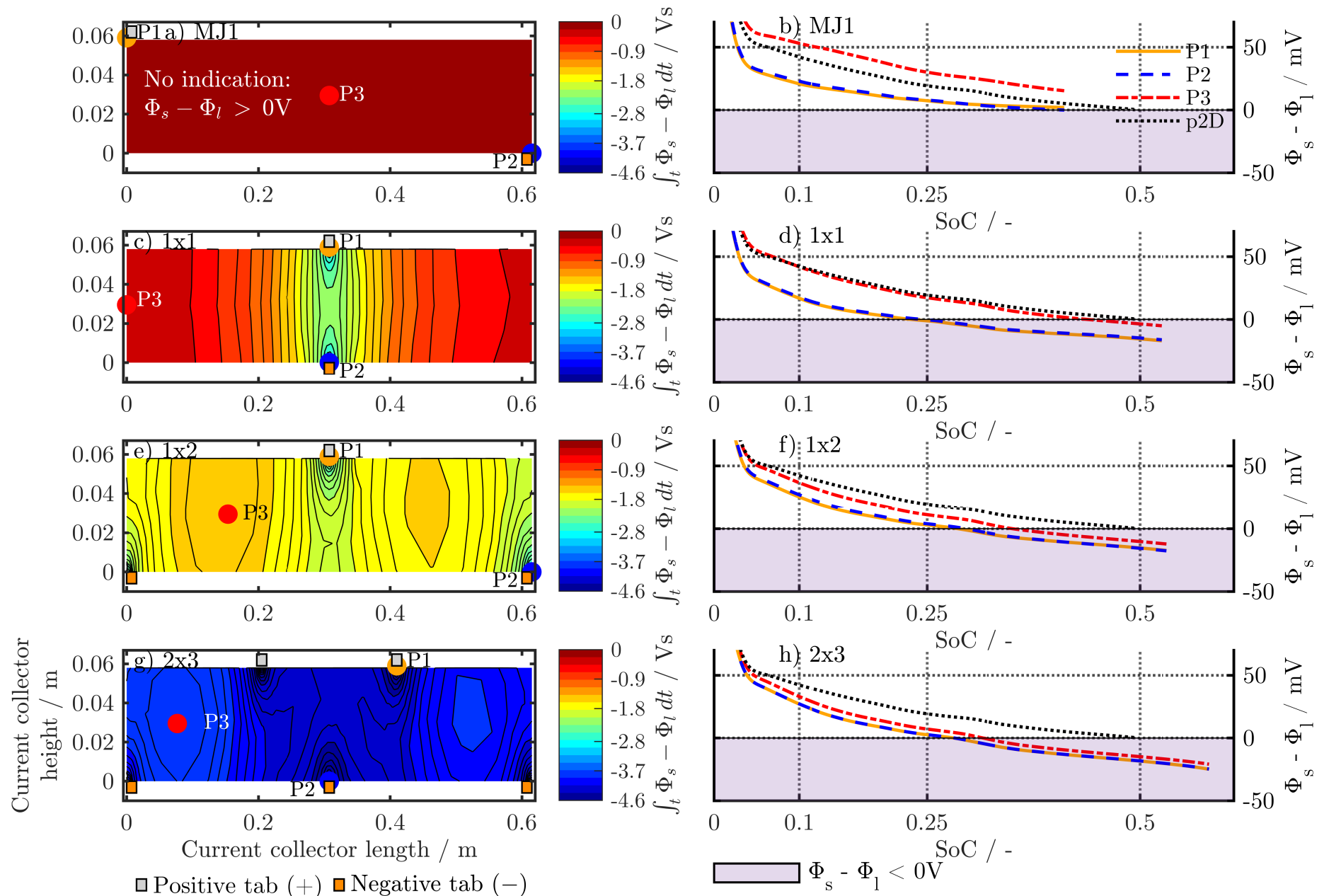

Figure 7: MuDiMod simulation results for single-tab $(\mathrm{MJ} 1,1 \times 1)$ and multi-tab design $(1 \times 2,2 \times 3)$ electrodes at high-rate $3 \mathrm{C}-\mathrm{CC}$ charging with the integrated (a, c, e and g, see Eq. 2) and transient (b, d, f and h) potential drop at the anode-separator interface to evaluate the tendency of lithium plating. As a reference, the single p2D simulation results are depicted as well (see b, d, f and h). 
However, a far more uniform temperature distribution with a maximum spread of $2 \mathrm{~K}$ and lower average temperatures is seen for the remaining tab patterns. The local temperature distribution at $3 \mathrm{C}$ and $\mathrm{EoC}$ is shown in the supplementary material of this work.

In sum, the MJ1 tab pattern avoids the onset of lithium plating during $3 \mathrm{C}-\mathrm{CC}$ thanks to the positive influence on reaction kinetics of its higher average temperature $\left(48.3^{\circ} \mathrm{C}\right)$ as compared to the remaining configurations $\left(45.8^{\circ} \mathrm{C}(1 \times 1), 45^{\circ} \mathrm{C}(1 \times 2)\right.$ and $\left.44.3^{\circ} \mathrm{C}(2 \times 3)\right)$. However, it promotes local overheating close to the tabs which is detrimental to the safety and lifetime of the cell. Reducing the pathway of the electrons along the electrode by $50 \%$ via using the $1 \mathrm{x} 1$ configuration, higher SoC levels compared to the MJ1 together with the earliest onset of lithium plating compared to the remaining models appears. In case of using the $1 \times 2$ or $2 \times 3$ tab pattern, the gained SoC level could be increased by further reducing ohmic losses on the current collector foils which is well in line with other works [39, 44, 46]. However, the simulation results suggest that, the more tabs are used, the more the potential drop decreases and the highest indication of lithium plating is seen for the $2 \times 3$ configuration. In the future, these simulation results shall be investigated experimentally by using lithium reference electrodes to measure local potentials $[27,36]$ during the charging process.

\subsection{Relative error between single p2D model and multi-dimensional model}

The simulation results of the single p2D model and the multi-dimensional model are shown in Fig. 7 b, d, f and h to evaluate the findings towards a homogeneously utilized electrode and determine the modeling error when using a single $\mathrm{p} 2 \mathrm{D}$. In the case of the MJ1 tab design, the single p2D model predicts 
a $20 \%$ higher cell SoC than the multi-dimensional model. In contrast, the p2D model underestimates the gained SoC level and does not indicate the onset of lithium plating for the alternative tab designs. Hence, neglecting the electrical configuration determines the simulation error of the p2D model. In addition, using a 0D thermal model limits the validity of the temperature calculation. The averaged single p2D simulation errors are summarized in Table 6 for the cell voltage, temperature and the potential drop at the anode-separator interface. To account for the model limitations when using

\begin{tabular}{|c|c|c|c|c|}
\hline & MJ1 & $1 \times 1$ & $1 \times 2$ & $2 \times 3$ \\
\hline$V_{\text {cell }} / \mathrm{mV}$ & 42 & 34 & 44 & 88 \\
\hline$T_{\text {cell }} / \mathrm{K}$ & 2.2 & 2.9 & 3.8 & 5.2 \\
\hline$\Phi_{s}-\Phi_{l} / \mathrm{mV}^{*}$ & 16 & 21 & 16 & 16 \\
\hline
\end{tabular}

a single p2D model for indication of lithium plating, the shown discrepancies in Table 6 for the potential drop can be used for adaption in terms of charge control algorithms as presented in Chu et al. [69].

\subsection{Modified CC-charging protocols}

To evaluate the CC-charging scenarios from $1 \mathrm{C}$ to $4 \mathrm{C}$ for all tab designs, the usable specific energy density is calculated from the amount of charge at EoC and the average of cell voltage from the MuDiMod simulation results as shown in Table 7. The usable amount of charge, which is probably affected by lithium plating, is approximated via Eq. 3 and referenced to the amount of charge at EoC. The calculated ratios correspond to the SoC range affected by lithium plating and are shown in Table 7 . Due to its poor electrical 
Table 7: Usable energy density and affected SoC range by lithium plating for CC-charging

\begin{tabular}{cccccccccc}
\hline & \multicolumn{3}{c}{ Usable specific energy } & \multicolumn{4}{c}{ Affected SoC range } \\
Charge-rate & \multicolumn{3}{c}{ density / } & $\mathbf{W h ~ k g}^{-1} \mathbf{*}$ & \multicolumn{3}{c}{ by $\Phi_{s}-\Phi_{l}<0$ V } & \% \\
& MJ1 & $\mathbf{1 x 1}$ & $\mathbf{1 x 2}$ & $\mathbf{2 x 3}$ & $\mathbf{M J 1}$ & $\mathbf{1 x 1}$ & $\mathbf{1 x 2}$ & $\mathbf{2 x 3}$ \\
\hline $\mathbf{1 C - C C}$ & 211 & 218 & 218 & 222 & 0 & 0 & 0 & 0 \\
$\mathbf{2 C}-\mathbf{C C}$ & 170 & 186 & 187 & 194 & 0 & 0 & 5.6 & 7 \\
3C-CC & 122 & 154 & 155 & 169 & 0 & 28.3 & 36 & 47.1 \\
4C-CC & 22 & 108 & 114 & 138 & 11.6 & 86.1 & 87.1 & 90.2 \\
\hline
\end{tabular}

* Ref. to cell weight of $45.8 \mathrm{~g}$ (MJ1)

configuration, the MJ1 design shows the highest decrease of specific energy with increasing C-rate, but also the lowest indication of lithium plating as the cut-off voltage is reached prematurely. The $1 \mathrm{x} 1$ and $1 \times 2$ design show quite similiar characteristics with lower usable energy loss but increased indication of lithium plating. The highest usable energy densities appear for the $2 \mathrm{x} 3$ design together with the highest indication of lithium plating which affects almost half of the usable charge at 3C-CC.

In order to achieve higher cell SoC levels at EoC and to reduce the SoC range affected by lithium plating, the $3 \mathrm{C}-\mathrm{CC}$ charging process is modified in this work. The modified charging strategies (MC) for all tab designs start with a charging rate of $3 \mathrm{C}$, subsequently switch to $2 \mathrm{C}$ and end at $4.2 \mathrm{~V}$. In case of the MJ1 design, the second, lower current stage helps to avoid premature EoC. In case of the other tab configurations (i.e. 1x1, 1x2 and $2 \times 3$ ), the first onset of lithium plating can be avoided (see Fig. 7 - P1 and P2). At the switching points, the applied charge rate is lowered and thus the polarization on the electrode is reduced. This results in increased potential drops $\Phi_{s}-\Phi_{l}>0 \mathrm{~V}$ and lower the affected SoC range by lithium plating. The switching point for the MJ1 design was set at $40.4 \%$ SoC and to $23.1 \%$ SoC, 
$28.6 \%$ SoC and $28.1 \%$ SoC for the $1 \times 1,1 \times 2$ and $2 \times 3$ design, respectively. In case of the $2 \times 3$ tab design, a third current stage at $1.5 \mathrm{C}$ was implemented at $62.6 \%$ SoC since lithium plating was indicated in the second current stage which affected approximately $14 \%$ of the SoC range.

The 3C-CC and MC charging strategies for all tab designs are shown in Fig. 8 vs. the cell SoC and the single p2D simulation results as a reference. Fig. $8 \mathrm{~b}$ shows the improvement of $\mathrm{SoC}$ at $\mathrm{EoC}$ for applying the MC strategy and for all tab designs SoC levels beyond $60 \%$ with marginal indication of lithium plating could be achieved compared to the standard 3C-CC. Regarding the single p2D simulation results, the switching point from $3 \mathrm{C}$ to $2 \mathrm{C}$ was set to $48.8 \% \mathrm{SoC}$ to avoid premature $\mathrm{EoC}$ by reaching the cut-off voltage. If a single p2D is used for evaluating fast charge protocols, adapation referring to the tab design as shown in Table 6 must be considered to avoid falsely predicted switching points.

Comparing standard $3 \mathrm{C}-\mathrm{CC}$ and $\mathrm{MC}$ charging with different tab designs, reductions of $99.7 \%, 99.2 \%$ and $99.6 \%$ of the affected SoC range by lithium plating and SoC increases of $+12.7,+12.2$ and $+15.8 \%$ for the $1 \times 1,1 \times 2$ and $2 \times 3$ tab design can be realized. Over $19.4 \%$ increase of usable capacity compared to 3C-CC could be simulated for the MJ1 configuration in $846 \mathrm{~s}$ and no tendency of lithium plating was observed.

In sum, the MC strategy increased the cell $\mathrm{SoC}$ at $\mathrm{EoC}$ and the simulated indicator states suggests prevention of lithium plating either by applying a global cell voltage or a local anode potential threshold. 

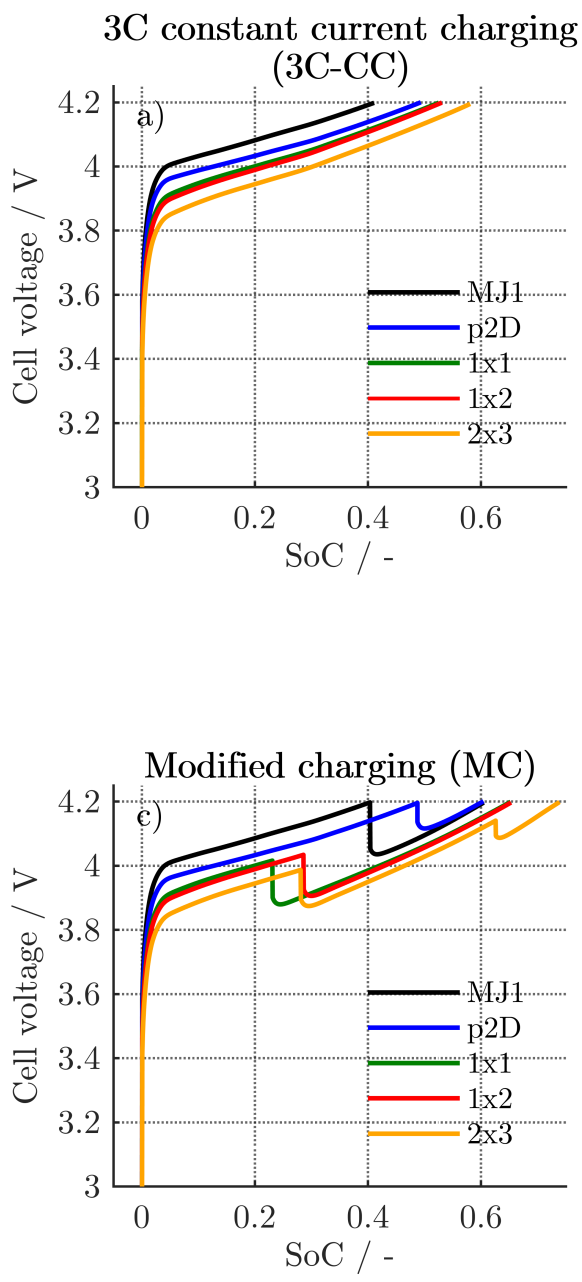

\section{Comparison of 3C-CC and MC}

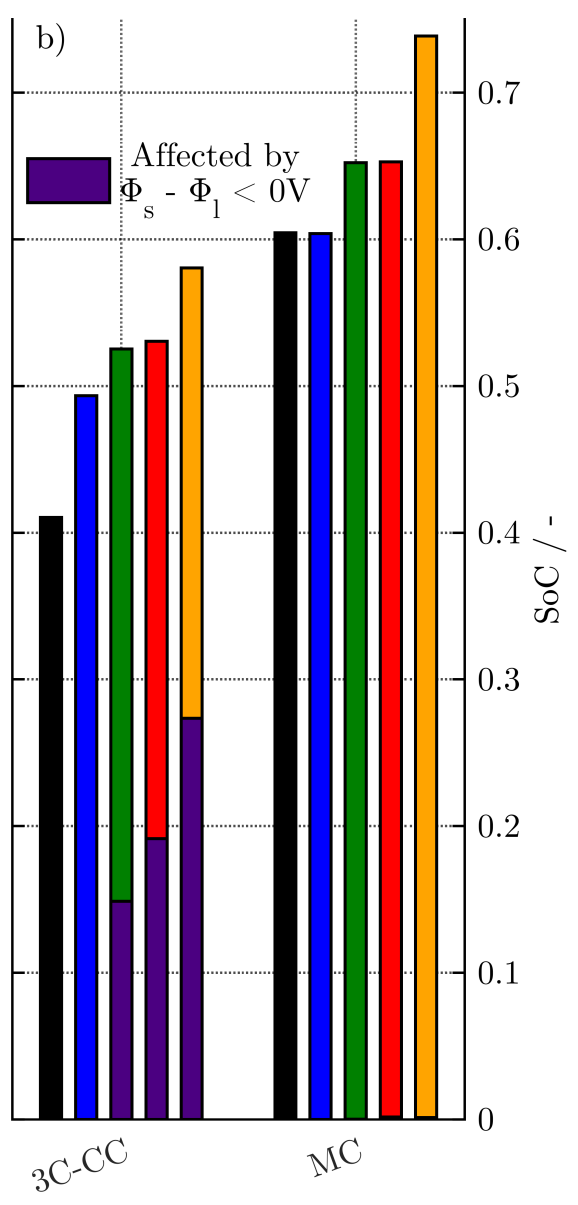

Figure 8: The 3C-CC (a) and the modified (c) charging strategy are illustrated by the cell voltage vs. the cell SoC (ref. to $3.35 \mathrm{Ah}$ ). The comparison of the gained cell SoC levels (b) for both charging strategies is shown with the affected SoC range by lithium plating (see Eq.3) in case of all tab designs and the single p2D model as a reference. 


\section{Conclusion}

A full electrochemical-thermal parameterization of a newman-type p2D model for a high-capacity and highly densified NMC-811/SiC electrode pair is presented, including measured open-circuit potentials and entropic coefficients. For both charge and discharge, DVA analysis of full and half cells revealed marginal deviations and simulation results for calorimetry and thermography measurements in a range of $20^{\circ} \mathrm{C}$ up to $40^{\circ} \mathrm{C}$ ambient temperature showed the validity of the presented parameterization. The charge-rate capability of high and low density electrodes was assessed by means of the single p2D model for both standard NMC-111/C and high-capacity NMC-811/SiC active material. Beyond $3 \mathrm{C}-\mathrm{CC}$, liquid transport limitation occurred. A higher tendency of lithium plating could be observed for NMC-111/C, likely due to lower maximum concentrations in the anode and a lower heat generation rate compared to NMC-811/SiC. Depending on the tab design, electrode utilization can be very non-uniform. Comparison of modeling results of the single p2D and the multi-dimensional model made it clear that a more detailed evaluation of the charging behavior should be based on the multidimensional model, especially when the onset of lithium plating needs to be estimated accurately. The multi-dimensional model results revealed that, with an effective electrode length of $61.5 \mathrm{~cm}$, a single tab design leads to local overheating and a relatively low end-of-charge SoC at high-rate CCcharging because the cut-off voltage is reached prematurely. However, no indication of lithium plating could be observed until 3C. Increasing the number of tabs or reducing the effective electrode length by $50 \%$ leads to a more homogenous temperature distribution, a lower average cell temperature, and 
increased end-of-charge SoC due to lower ohmic losses in the current collectors. However, more tabs and decreased effective electrode length also result in a higher likelihood of lithium plating. Optimized, two- or three-stage CCcharging protocols were derived from the multi-dimensional model results by defining a switching point either based on cell voltage or on local anode overpotential to account for the onset of lithium plating. The charge protocols allow charging to SoC levels above $60 \%$ within 18 min with minimal risk of lithium plating.

In future work, the models presented in this work could be extended by a multi-particle approach to account also for smaller sized particles which may affect the lithium plating characteristic or by locally calculated lithium plating kinetics. We think there are plentiful applications to the presented multi-dimensional model, e. g. the investigation of tab-cooling techniques that have been proposed to reduce local overheating [81]. 


\section{Acknowledgement}

This work has received funding from the European Union's Horizon 2020 research and innovation programme under the grant 'Electric Vehicle Enhanced Range, Lifetime And Safety Through INGenious battery management' [EVERLASTING-713771].

\section{Appendix A.}

Table A.8: Calculation of heat transfer coefficient at convective air-cooling during infrared thermography measurements

\begin{tabular}{|c|c|c|c|}
\hline \multicolumn{4}{|c|}{ Physical properties ${ }^{\mathrm{I}}$ of dry air at $25^{\circ} \mathrm{C}$ and 1 bar ambient pressure } \\
\hline Heat capacity & $c_{p, \text { air }}$ & \multicolumn{2}{|c|}{$1007 \mathrm{Jkg}^{-1} \mathrm{~K}^{-1}$} \\
\hline Thermal conductivity & $\lambda_{\text {air }}$ & \multicolumn{2}{|c|}{$0.0255 \mathrm{Wm}^{-1} \mathrm{~K}^{-1}$} \\
\hline Dynamic viscosity & $\eta_{\text {air }}$ & \multicolumn{2}{|c|}{$1.8483 \times 10^{-5} \mathrm{Ns} \mathrm{m}^{-2}$} \\
\hline Density & $\rho_{\text {air }}$ & \multicolumn{2}{|c|}{$1.1846 \mathrm{~kg} \mathrm{~m}^{-3}$} \\
\hline Prandtl number & $\operatorname{Pr}$ & \multicolumn{2}{|c|}{$\eta_{\text {air }} \cdot c_{\mathrm{p}, \text { air }} \cdot \lambda_{\text {air }}^{-1}=0.7299$} \\
\hline \multicolumn{4}{|c|}{ Heat transfer coefficient under forced convective air-flow ${ }^{I I}$} \\
\hline Characteristic length & $\mathrm{L}$ & \multicolumn{2}{|l|}{$18.7 \mathrm{~cm}^{\text {III }}$} \\
\hline Velocity & $\mathrm{v}_{\text {air }}$ & $1 \mathrm{~ms}^{-1}$ & $2 \mathrm{~ms}^{-1}$ \\
\hline Reynolds number & $\operatorname{Re}$ & $\rho_{\text {air }} \cdot \mathrm{v}_{\text {air }} \cdot \mathrm{L} \cdot \eta_{\text {air }}=1229.4$ & 2235.9 \\
\hline Nusselt number & $\mathrm{Nu}$ & $0.25 \cdot \operatorname{Re}^{0.6} \cdot \operatorname{Pr}^{0.38}=15.8$ & 22.7 \\
\hline Heat transfer Coefficient & $\alpha_{\text {air }}$ & $\mathrm{Nu} \cdot \lambda_{\text {air }} \cdot \mathrm{L}^{-1}=22.1 \mathrm{Wm}^{-2} \mathrm{~K}^{-1}$ & $31.7 \mathrm{Wm}^{-2} \mathrm{~K}^{-1}$ \\
\hline
\end{tabular}

I Ref. [82] II Ref. [83] III Ref. [21] 
Table A.9: Properties of the electrolyte and the current collectors

\begin{tabular}{|c|c|c|}
\hline Electrolyte & \multicolumn{2}{|c|}{$1 \mathrm{M} \mathrm{LiPF}_{6}$ in $\mathrm{PC} / \mathrm{EC} / \mathrm{DMC}$} \\
\hline Salt diffusivity $D_{l}^{\mathrm{I}} / \mathrm{m}^{2} \mathrm{~s}^{-1}$ & \multicolumn{2}{|c|}{$10 \mathrm{E}-4 \cdot 10^{-4.43-\frac{54}{T-229-5 c_{l}}-0.22 c_{l}}$} \\
\hline Ionic conductivity $\kappa_{l}{ }^{\mathrm{I}} / \mathrm{S} \mathrm{m}^{-1}$ & \multicolumn{2}{|c|}{$\begin{array}{l}0.1 c_{l}\left(-10.5+0.668 c_{l}+0.494 c_{l}^{2}+0.074 T-0.0178 c_{l} T\right. \\
\left.\quad-8.8610^{-4} c_{l}^{2} T-6.9610^{-5} T^{2}+2.810^{-5} c_{l} T^{2}\right)^{2}\end{array}$} \\
\hline Activity $\frac{d \ln f_{ \pm}}{d \ln c_{l}} \mathrm{I} /-$ & \multirow{2}{*}{\multicolumn{2}{|c|}{$\begin{array}{c}\left(0.601-0.24 c_{l}^{0} .5+0.983(1-0.0052(T-294)) c_{l}^{1.5}\right) \cdot\left(1-t_{+}^{0}\right)^{-1}-1 \\
0.38\end{array}$}} \\
\hline Transference $t_{+}^{0} \mathrm{I} /-$ & & \\
\hline Ref. concentration $c_{r e f}{ }^{\mathrm{I}} / \mathrm{mol} \mathrm{m}^{-3}$ & \multicolumn{2}{|l|}{1000} \\
\hline Current Collector & Copper & Aluminum \\
\hline Height $H / \mathrm{cm}$ & $5.8^{*}$ & $5.8^{*}$ \\
\hline Length $W / \mathrm{cm}$ & $61.5^{*}$ & $61.5^{*}$ \\
\hline Electrical conductivity $\sigma_{c c} / \mathrm{S} \mathrm{m}^{-1}$ & $\frac{5.96 \cdot 10^{7}}{1+3.383 \cdot 10^{-3}(T-293.15 \mathrm{~K})} \mathrm{S} \mathrm{m}^{-1} \mathrm{II}$ & $\frac{3.78 \cdot 10^{7}}{1+4.290 \cdot 10^{-3}(T-293.15 \mathrm{~K})}$ III \\
\hline
\end{tabular}

I Ref. [65] II Ref. [84] III Ref. [85] * Measured and idealized for 2D electrical model 
Table A.10: Thermal parameterization of the single components and the electrode stack

\begin{tabular}{|c|c|c|c|c|c|c|c|}
\hline \multirow{2}{*}{\multicolumn{2}{|c|}{ Properties of single layers }} & \multicolumn{2}{|c|}{ Anode } & \multirow{2}{*}{ Separator ${ }^{*}$} & \multicolumn{2}{|c|}{ Cathode } & \multirow{2}{*}{ Electrolyte } \\
\hline & & Copper & $\mathrm{SiC}$ & & NMC-811 & Aluminum & \\
\hline Thickness & $L$ in $\mu \mathrm{m}$ & 11 & 86.7 & 12 & 66.2 & 17.3 & - \\
\hline Density ${ }^{\mathrm{I}}$ & $\rho$ in $\mathrm{kg} \mathrm{m}^{-3}$ & $8950^{\mathrm{II}}$ & $2242^{\mathrm{III}}$ & 1009 & $4870^{\mathrm{IV}}$ & $2710^{\mathrm{II}}$ & 1130 \\
\hline Heat capacity ${ }^{\mathrm{I}}$ & $c_{p}$ in $\mathrm{J} \mathrm{kg}^{-1} \mathrm{~K}^{-1}$ & 385 & $867 \mathrm{~V}$ & 1978.2 & $840.1^{\mathrm{VI}}$ & 903 & 2055.1 \\
\hline Heat conductivity ${ }^{\mathrm{I}}$ & $\lambda$ in $\mathrm{W} \mathrm{m}^{-1} \mathrm{~K}^{-1}$ & 398 & 1.04 & 0.33 & 1.58 & 238 & 0.6 \\
\hline \multicolumn{2}{|c|}{ Properties of electrode stack ${ }^{\mathrm{I}, * *}$} & \multicolumn{6}{|c|}{ Effective values } \\
\hline Thickness & $L_{\text {stack }}$ in $\mu \mathrm{m}$ & \multirow{3}{*}{\multicolumn{6}{|c|}{$\begin{array}{c}L_{c c,-}+2 \cdot\left(L_{n e g}+L_{s e p}+L_{p o s}\right)+L_{c c,+}=358 \\
\frac{\sum_{i} L_{i} \cdot \rho_{i}}{L_{s t a c k}}=2761.7 \\
\frac{\sum_{i} L_{i} \cdot c_{i} \cdot c_{p, i}}{L_{s t a c k} \cdot \rho_{s t a c k}}=918.8\end{array}$}} \\
\hline Density $^{\mathrm{I}}$ & $\rho_{\text {stack }}$ in $\mathrm{kg} \mathrm{m}^{-3}$ & & & & & & \\
\hline Heat capacity ${ }^{\mathrm{I}}$ & $c_{\text {stack }}$ in $\mathrm{J} \mathrm{kg}^{-1} \mathrm{~K}^{-1}$ & & & & & & \\
\hline \multirow[t]{2}{*}{ Heat conductivity ${ }^{\text {I }}$} & $\lambda_{\perp}$ in $\mathrm{W} \mathrm{m}^{-1} \mathrm{~K}^{-1}$ & \multicolumn{6}{|c|}{$\left(\frac{1}{L_{s t a c k}} \cdot \sum_{i} \frac{L_{i}}{\lambda_{p, i}}\right)^{-1}=2.3$} \\
\hline & $\lambda_{\|}$in $\mathrm{W} \mathrm{m}^{-1} \mathrm{~K}^{-1}$ & \multicolumn{6}{|c|}{$\frac{\sum_{i} L_{i} \cdot \lambda_{p, i}}{L_{s, a c k}}=24.3$} \\
\hline
\end{tabular}

I if not indicated otherwise, the properties and calculation are taken from Ref. [86]

II Ref. [52] III Ref. [10] IV Ref. [7] V Ref. [87] VI Ref. [88]

* Polyolefin ** Porous material superimposed of solid and liquid phase 
Table A.11: Parameterization of the single p2D model with NMC-111/C electrodes

\begin{tabular}{lccc}
\hline Geometry & Graphite $(\mathbf{C})$ & Separator & NMC-111 \\
\hline Thickness $L$ & $86.7 \mu^{\mathrm{m}}$ & $12 \mu \mathrm{m}^{\mathrm{m}}$ & $66.2 \mathrm{\mu m}^{\mathrm{m}}$ \\
Particle radius $R_{p}$ & $11 \mu \mathrm{m}^{\mathrm{I}, \mathrm{D} 50}$ & & $5 \mu \mathrm{m}^{\mathrm{II}, \mathrm{D} 50}$ \\
Active material fraction $\varepsilon_{s}$ & $0.45^{\mathrm{I}}$ & & $0.38^{\mathrm{I}}$ \\
Inactive fraction $\varepsilon_{s, n a}$ & $0.05^{\mathrm{I}}$ & & $0.17^{\mathrm{I}}$ \\
Porosity $\varepsilon_{l}$ & $0.5^{\mathrm{I}}$ & $0.5^{\mathrm{I}}$ & $0.45^{\mathrm{I}}$ \\
Bruggeman coefficient $\beta^{\mathrm{IV}, *}$ & 1.5 & 1.5 & 1.5 \\
Thermodynamics & & &
\end{tabular}

Equilibrium potential $E_{e q}$

Ref. [24]

Ref. [24]

Entropic coefficient $\frac{\partial E_{e q}}{\partial T}$

Ref. [73]

Ref. [73]

Stoichiometry $100 \% \mathrm{SoC}$

0.76

0.39

$0 \% \mathrm{SoC}$

0.006

0.94

Max. concentration $c_{s, \max }$

$31360 \mathrm{~mol} \mathrm{~m}^{-3}$ II

$52500 \mathrm{~mol} \mathrm{~m}^{-3}$ II

Transport

$\begin{array}{lcc}\text { Solid diffusivity } D_{s}^{* *} & 5 \times 10^{-14} \mathrm{~m}^{2} \mathrm{~s}^{-1 \mathrm{I}} & 5 \times 10^{-13} \mathrm{~m}^{2} \mathrm{~s}^{-1 \mathrm{I}} \\ \text { Specific activation } \frac{E_{a, D_{s}} * *}{R} & 1200 \mathrm{~K}^{\mathrm{e}} & 1200 \mathrm{~K}^{\mathrm{e}} \\ \text { Solid conductivity } \sigma_{s} & 100 \mathrm{~S} \mathrm{~m}^{-1} \mathrm{I} & 3.8 \mathrm{~S} \mathrm{~m}^{-1} \mathrm{I} \\ \text { Film resistance } R_{f} & 0.0035 \Omega \mathrm{m}^{2} \mathrm{III} & 0 \Omega \mathrm{m}^{2} \mathrm{e} \\ \text { Kinetics } & & 6 \times 10^{-12} \mathrm{~m} \mathrm{~s}^{-1 \mathrm{I}} \\ \text { Reaction rate constant } k^{* *} & 2.22 \times 10^{-11} \mathrm{~m} \mathrm{~s}^{-1 \mathrm{I}} & 3600 \mathrm{~K}^{\mathrm{e}} \\ \text { Specific activation } \frac{E_{a, k} * *}{R} & 3600 \mathrm{~K}^{\mathrm{e}} & 0.5 \mathrm{e} \\ \text { Transfer coefficient } \alpha_{a / c} & 0.5 & \mathrm{e}\end{array}$

I Ref. [24] II Ref. [78] III Ref. [20] IV Ref. [63] $\mathrm{m}=$ measured $\quad \mathrm{e}=$ estimated

* Effective transport correction according to Bruggeman (Ref. [63]): $\Psi_{\text {eff }}=\varepsilon^{\beta} \cdot \Psi_{0}$

** Arrhenius law (Ref. [64]): $k=A \cdot \exp \left(\frac{E_{a, i}}{R} \frac{(T-298[\mathrm{~K}])}{T \cdot 298[\mathrm{~K}]}\right)$ 
Table A.12: Equations for the single p2D, 2D electrical and 3D thermal model

Electrochemical-thermal model (single p2D)

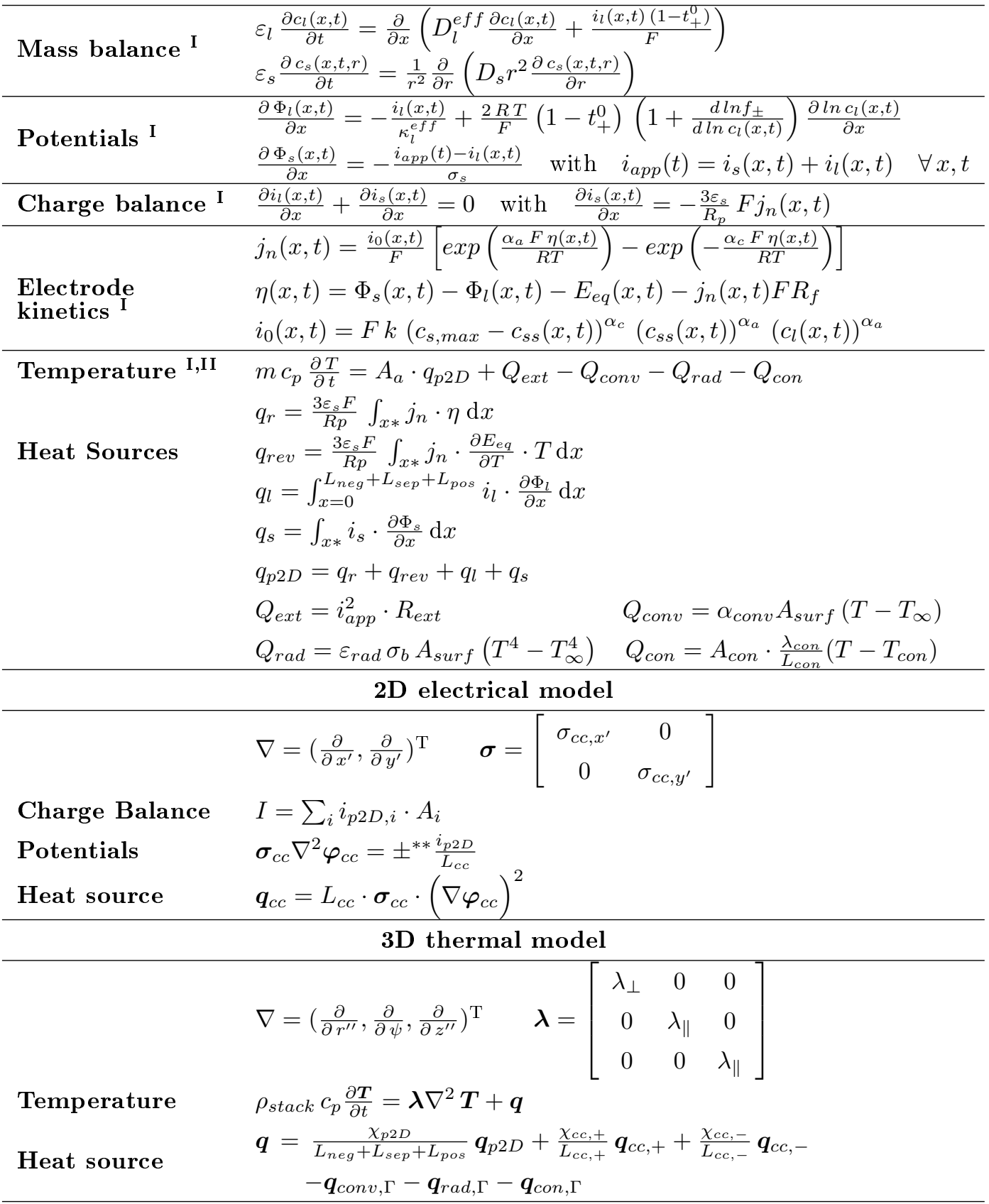

I Ref. [22] II Ref. [89] $\Gamma$ Only at the surface of the jelly roll

$x *=x \in\left[0, L_{n e g}\right] \wedge\left[L_{n e g}+L_{\text {sep }}, L_{n e g}+L_{\text {sep }}+L_{\text {pos }}\right] \quad * *<0$ for $\mathrm{cc},-$ and $>0 \mathrm{cc},+$ 
Table A.13: Nomenclature I

\begin{tabular}{|c|c|c|}
\hline \multicolumn{3}{|c|}{ Greek symbols } \\
\hline$\alpha$ & & Transfer coefficient \\
\hline$\alpha_{c o n v}$ & $\mathrm{~W} \mathrm{~m} \mathrm{~m}^{-2} \mathrm{~K}^{-1}$ & Heat transfer coefficient \\
\hline$\beta$ & & Bruggeman coefficient \\
\hline$\varepsilon$ & & Volume fraction \\
\hline$\varepsilon_{\text {rad }}$ & & Radiation emission coefficient \\
\hline$\epsilon$ & & Numerical tolerance \\
\hline$\eta$ & $\mathrm{V}$ & Overpotential \\
\hline$\kappa$ & $\mathrm{S} \mathrm{m}^{-1}$ & Ionic conductivity \\
\hline$\lambda$ & $\mathrm{W} \mathrm{m}^{-1} \mathrm{~K}^{-1}$ & Heat conductivity \\
\hline$\Lambda$ & $\mathrm{m}$ & Arc length \\
\hline$\rho$ & $\mathrm{kg} \mathrm{m}^{-3}$ & Mass density \\
\hline$\sigma$ & $\mathrm{S} \mathrm{m}^{-1}$ & Electrical conductivity \\
\hline$\sigma_{b}$ & $5.67 \times 10^{-8} \mathrm{~W} \mathrm{~m}^{-2} \mathrm{~K}^{-4}$ & Stefan-Boltzmann constant \\
\hline$\tau$ & & Tortuosity \\
\hline$\Phi$ & $\mathrm{V}$ & Electrical potential \\
\hline$\psi$ & $\mathrm{rad}$ & Azimuthal-coordinate in 3D model \\
\hline$\Psi_{\text {arc }}$ & $\mathrm{rad}$ & Azimuthal angle \\
\hline$\chi$ & & Thickness ratio \\
\hline \multicolumn{3}{|c|}{ Indices } \\
\hline $\mathrm{a}$ & \multicolumn{2}{|c|}{ anodic reaction (oxidation) } \\
\hline $\mathrm{c}$ & \multicolumn{2}{|c|}{ cathodic reaction (reduction) } \\
\hline $\mathrm{cc}$ & \multicolumn{2}{|l|}{ current collector } \\
\hline con & \multicolumn{2}{|l|}{ Heat conduction } \\
\hline conv & \multicolumn{2}{|c|}{ Heat convection } \\
\hline eff & \multicolumn{2}{|c|}{ Transport corrected (Bruggeman correlation[63]) } \\
\hline ext & \multicolumn{2}{|c|}{ External heat (i.e. from grid resistance) } \\
\hline 1 & \multicolumn{2}{|c|}{ Liquid phase (i.e. Electrolyte) } \\
\hline neg & \multicolumn{2}{|c|}{ Negative electrode } \\
\hline pos & \multicolumn{2}{|l|}{ Positive electrode } \\
\hline $\mathrm{rad}$ & \multicolumn{2}{|l|}{ Heat radiation } \\
\hline $\mathrm{r}$ & \multicolumn{2}{|l|}{ Reaction heat } \\
\hline rev & \multicolumn{2}{|l|}{ Reversible heat } \\
\hline s & \multicolumn{2}{|c|}{ Solid phase (i.e. Active particle) } \\
\hline sep & \multicolumn{2}{|c|}{ Separator } \\
\hline SS & \multicolumn{2}{|c|}{ Solid phase (i.e. Active particle surface) } \\
\hline stack & \multicolumn{2}{|c|}{ Electrode stack } \\
\hline surf & \multicolumn{2}{|l|}{ Surface } \\
\hline+ & \multicolumn{2}{|l|}{ Positive current collector } \\
\hline- & \multicolumn{2}{|l|}{ Negative current collector } \\
\hline
\end{tabular}


Table A.14: Nomenclature II

\begin{tabular}{|c|c|c|}
\hline \multicolumn{3}{|c|}{ Latin symbols } \\
\hline$a$ & $\mathrm{~m}^{-1}$ & Specific surface \\
\hline$b_{g}$ & $\mathrm{mAhg}^{-1}$ & Maximum theoretical loading \\
\hline$c$ & $\mathrm{~mol} \mathrm{~m}^{-3}$ & Concentration of lithium cations $\left(\mathrm{Li}^{+}\right)$ \\
\hline$c_{s, \max }$ & $\mathrm{mol} \mathrm{m}^{-3}$ & Maximum theoretical concentration of $\mathrm{Li}^{+}$ \\
\hline$c_{p}$ & $\mathrm{~J} \mathrm{~kg}^{-1} \mathrm{~K}^{-1}$ & Heat capacity \\
\hline$D$ & $\mathrm{~m}^{2} \mathrm{~s}^{-1}$ & Diffusion coefficient \\
\hline$E_{e q}$ & $\mathrm{~V}$ & Equilibrium potential vs. $\mathrm{Li} / \mathrm{Li}^{+}$ \\
\hline$f_{ \pm}$ & & Mean molar activity coefficient of electrolyte \\
\hline$F$ & $96485 \mathrm{As} \mathrm{mol}^{-1}$ & Faraday's constant \\
\hline$H$ & $\mathrm{~m}$ & Height of electrode/current collector \\
\hline$i$ & $\mathrm{Am}^{-2}$ & Current density \\
\hline$I$ & $\mathrm{~A}$ & Applied current \\
\hline$i_{a p p}$ & $\mathrm{Am}^{-2}$ & Applied current density \\
\hline$i_{n}$ & $\mathrm{~A} \mathrm{~m}^{-2}$ & Current density perpendicular to particle surface \\
\hline$i_{p 2 D}$ & $\mathrm{~A} \mathrm{~m}^{-2}$ & Current density perpendicular to current collectors \\
\hline$i_{0}$ & $\mathrm{Am}^{-2}$ & Exchange current density \\
\hline$j_{n}$ & $\mathrm{~mol} \mathrm{~m}^{-2} \mathrm{~s}^{-1}$ & Pore-wall flux \\
\hline$k$ & $\mathrm{~m} \mathrm{~s}^{-1}$ & Reaction rate constant \\
\hline$L$ & $\mathrm{~m}$ & Thickness \\
\hline$m$ & $\mathrm{~kg}$ & Mass of the jelly roll \\
\hline$r$ & $\mathrm{~m}$ & Radial-coordinate in active particles of $\mathrm{p} 2 \mathrm{D}$ model \\
\hline$r^{\prime \prime}$ & $\mathrm{m}$ & Radial-coordinate in 3D model \\
\hline$R$ & $8.314 \mathrm{~J} \mathrm{~mol}^{-1} \mathrm{~K}^{-1}$ & Gas constant \\
\hline$R_{e x t}$ & $\Omega \mathrm{m}^{2}$ & Grid resistance \\
\hline$R_{f}$ & $\Omega \mathrm{m}^{2}$ & Surface-layer resistance \\
\hline$R_{p}$ & $\mathrm{~m}$ & Particle radius \\
\hline$q$ & $\mathrm{~W} \mathrm{~m}^{-2}$ & Heat generation rate per area \\
\hline$Q$ & $\mathrm{~W}$ & Heat generation rate \\
\hline$t$ & $\mathrm{~s}$ & Time \\
\hline$T$ & $\mathrm{~K}$ & Temperature \\
\hline$t_{+}^{0}$ & & Transport number of $\mathrm{Li}^{+}$ \\
\hline$W$ & $\mathrm{~m}$ & Length of electrode/current collector \\
\hline$x$ & $\mathrm{~m}$ & $\mathrm{x}$-coordinate in $\mathrm{p} 2 \mathrm{D}$ model \\
\hline$x^{\prime}$ & $\mathrm{m}$ & $\mathrm{x}$-coordinate in $2 \mathrm{D}$ model \\
\hline$y^{\prime}$ & $\mathrm{m}$ & $\mathrm{y}$-coordinate in $2 \mathrm{D}$ model \\
\hline$x^{\prime \prime}$ & $\mathrm{m}$ & $\mathrm{x}$-coordinate in $3 \mathrm{D}$ model \\
\hline$y^{\prime \prime}$ & $\mathrm{m}$ & $\mathrm{y}$-coordinate in $3 \mathrm{D}$ model \\
\hline$z^{\prime \prime}$ & $\mathrm{m}$ & z-coordinate in $3 \mathrm{D}$ model \\
\hline
\end{tabular}




\section{References}

[1] D. Andre, S.-J. Kim, P. Lamp, S. F. Lux, F. Maglia, O. Paschos, B. Stiaszny, Future generations of cathode materials: An automotive industry perspective, J. Mater. Chem. A 3 (13) (2015) 6709-6732. doi:10.1039/C5TA00361J.

[2] A. Chatelain, M. Erriquez, P.-Y. Moulière, P. Schäfer, What a teardown of the latest electric vehicles reveals about the future of mass-market evs, url: https://www.mckinsey.com/industries/automotive-andassembly/our-insights / what-a-teardown-of-the-latest-electric-vehiclesreveals-about-the-future-of-mass-market-evs (2018).

[3] S.-T. Myung, F. Maglia, K.-J. Park, C. S. Yoon, P. Lamp, S.-J. Kim, Y.-K. Sun, Nickel-rich layered cathode materials for automotive lithiumion batteries: Achievements and perspectives, ACS Energy Letters 2 (1) (2016) 196-223. doi:10.1021/acsenergylett.6b00594.

[4] T. Liang, Advanced xev battery development at catl, aabc europe advanced automotive battery conference (2017) 1-15.

[5] G. E. Blomgren, The development and future of lithium ion batteries, Journal of The Electrochemical Society 164 (1) (2016) A5019-A5025. doi:10.1149/2.0251701jes.

[6] H.-J. Noh, S. Youn, C. S. Yoon, Y.-K. Sun, Comparison of the structural and electrochemical properties of layered li(ni_xco_ymn_z)o2 $(\mathrm{x}=1 / 3, \quad 0.5, \quad 0.6, \quad 0.7, \quad 0.8$ and 0.85$)$ cathode material for 
lithium-ion batteries, Journal of Power Sources 233 (2013) 121-130. doi:10.1016/j.jpowsour.2013.01.063.

[7] R. Jung, M. Metzger, F. Maglia, C. Stinner, H. A. Gasteiger, Oxygen release and its effect on the cycling stability of linixmnycozo2 (nmc) cathode materials for li-ion batteries, Journal of The Electrochemical Society 164 (7) (2017) A1361-A1377. doi:10.1149/2.0021707jes.

[8] Z. Luo, D. Fan, X. Liu, H. Mao, C. Yao, Z. Deng, High performance silicon carbon composite anode materials for lithium ion batteries, Journal of Power Sources 189 (1) (2009) 16-21. doi:10.1016/j.jpowsour.2008.12.068.

[9] J.-Y. Li, Q. Xu, G. Li, Y.-X. Yin, L.-J. Wan, Y.-G. Guo, Research progress regarding si-based anode materials towards practical application in high energy density li-ion batteries, Mater. Chem. Front. 1 (9) (2017) 1691-1708. doi:10.1039/C6QM00302H.

[10] R. Dash, S. Pannala, Theoretical limits of energy density in siliconcarbon composite anode based lithium ion batteries: Supplementary information, Scientific reports 6 (2016) 27449. doi:10.1038/srep27449.

[11] N. Dimov, S. Kugino, M. Yoshio, Mixed silicon-graphite composites as anode material for lithium ion batteries, Journal of Power Sources 136 (1) (2004) 108-114. doi:10.1016/j.jpowsour.2004.05.012.

[12] H. Zhang, X. Li, H. Guo, Z. Wang, Y. Zhou, Hollow si/c composite as anode material for high performance lithium-ion battery, Powder Technology 299 (2016) 178-184. doi:10.1016/j.powtec.2016.05.002. 
[13] B. Fuchsbichler, C. Stangl, H. Kren, F. Uhlig, S. Koller, High capacity graphite-silicon composite anode material for lithium-ion batteries, Journal of Power Sources 196 (5) (2011) 2889-2892. doi:10.1016/j.jpowsour.2010.10.081.

[14] Z. Du, J. Li, C. Daniel, D. L. Wood, Si alloy/graphite coating design as anode for li-ion batteries with high volumetric energy density, Electrochimica Acta 254 (2017) 123-129. doi:10.1016/j.electacta.2017.09.087.

[15] C. K. Chan, H. Peng, G. Liu, K. McIlwrath, X. F. Zhang, R. A. Huggins, Y. Cui, High-performance lithium battery anodes using silicon nanowires, Nature nanotechnology 3 (1) (2008) 31-35. doi:10.1038/nnano.2007.411.

[16] T. D. Hatchard, J. R. Dahn, In situ xrd and electrochemical study of the reaction of lithium with amorphous silicon, Journal of The Electrochemical Society 151 (6) (2004) A838. doi:10.1149/1.1739217.

[17] J.-H. Lee, W.-J. Kim, J.-Y. Kim, S.-H. Lim, S.-M. Lee, Spherical silicon/graphite/carbon composites as anode material for lithiumion batteries, Journal of Power Sources 176 (1) (2008) 353-358. doi:10.1016/j.jpowsour.2007.09.119.

[18] M.-Q. Li, M.-Z. Qu, X.-Y. He, Z.-L. Yu, Effects of electrolytes on the electrochemical performance of si/graphite/disordered carbon composite anode for lithium-ion batteries, Electrochimica Acta 54 (19) (2009) 4506-4513. doi:10.1016/j.electacta.2009.03.046. 
[19] J. Smekens, J. Paulsen, W. Yang, N. Omar, J. Deconinck, A. Hubin, J. van Mierlo, A modified multiphysics model for lithium-ion batteries with a lixni1/3mn1/3co1/3o2 electrode, Electrochimica Acta 174 (2015) 615-624. doi:10.1016/j.electacta.2015.06.015.

[20] J. Mao, W. Tiedemann, J. Newman, Simulation of temperature rise in li-ion cells at very high currents, Journal of Power Sources 271 (2014) 444-454. doi:10.1016/j.jpowsour.2014.08.033.

[21] LG Chem Mobile Battery Division, Technical information of lgc inr18650mj1 (2015).

URL http://www.lgchem.com

[22] M. Doyle, T. F. Fuller, J. Newman, Modeling of galvanostatic charge and discharge of the lithium/polymer/insertion cell, Journal of The Electrochemical Society 140 (6) (1993) 1526-1533.

[23] S. V. Erhard, P. J. Osswald, J. Wilhelm, A. Rheinfeld, S. Kosch, A. Jossen, Simulation and measurement of local potentials of modified commercial cylindrical cells: Ii: Multi-dimensional modeling and validation, Journal of The Electrochemical Society 162 (14) (2015) A2707A2719. doi:10.1149/2.0431514jes.

[24] S. V. Erhard, P. J. Osswald, P. Keil, E. Höffer, M. Haug, A. Noel, J. Wilhelm, B. Rieger, K. Schmidt, S. Kosch, F. M. Kindermann, F. Spingler, H. Kloust, T. Thoennessen, A. Rheinfeld, A. Jossen, Simulation and measurement of the current density distribution in lithium-ion batteries 
by a multi-tab cell approach, Journal of The Electrochemical Society 164 (1) (2017) A6324-A6333. doi:10.1149/2.0551701jes.

[25] B. Rieger, S. V. Erhard, S. Kosch, M. Venator, A. Rheinfeld, A. Jossen, Multi-dimensional modeling of the influence of cell design on temperature, displacement and stress inhomogeneity in large-format lithium-ion cells, Journal of The Electrochemical Society 163 (14) (2016) A3099A3110. doi:10.1149/2.1051614jes.

[26] S. Kosch, Y. Zhao, J. Sturm, J. Schuster, G. Mulder, E. Ayerbe, A. Jossen, A computationally efficient multi-scale model for lithium-ion cells, Journal of The Electrochemical Society 165 (10) (2018) A2374A2388. doi:10.1149/2.1241810jes.

[27] T. Amietszajew, E. McTurk, J. Fleming, R. Bhagat, Understanding the limits of rapid charging using instrumented commercial 18650 high-energy li-ion cells, Electrochimica Acta 263 (2018) 346-352. doi:10.1016/j.electacta.2018.01.076.

[28] M. W. Verbrugge, C. W. Wampler, On the optimal sizing of batteries for electric vehicles and the influence of fast charge, Journal of Power Sources 384 (2018) 312-317. doi:10.1016/j.jpowsour.2018.02.064.

[29] F. B. Spingler, W. Wittmann, J. Sturm, B. Rieger, A. Jossen, Optimum fast charging of lithium-ion pouch cells based on local volume expansion criteria, Journal of Power Sources 393 (2018) 152-160. doi:10.1016/j.jpowsour.2018.04.095. 
[30] T. R. Tanim, M. G. Shirk, R. L. Bewley, E. J. Dufek, B. Y. Liaw, Fast charge implications: Pack and cell analysis and comparison, Journal of Power Sources 381 (2018) 56-65. doi:10.1016/j.jpowsour.2018.01.091.

[31] T. Hutzenlaub, A. Asthana, J. Becker, D. R. Wheeler, R. Zengerle, S. Thiele, Fib/sem-based calculation of tortuosity in a porous licoo2 cathode for a li-ion battery, Electrochemistry Communications 27 (2013) 77-80. doi:10.1016/j.elecom.2012.11.006.

[32] A. Senyshyn, M. J. Mühlbauer, O. Dolotko, M. Hofmann, H. Ehrenberg, Homogeneity of lithium distribution in cylinder-type li-ion batteries, Scientific reports 5 (2015) 18380. doi:10.1038/srep18380.

[33] L. Zielke, T. Hutzenlaub, D. R. Wheeler, C.-W. Chao, I. Manke, A. Hilger, N. Paust, R. Zengerle, S. Thiele, Three-phase multiscale modeling of a licoo 2 cathode: Combining the advantages of fib-sem imaging and x-ray tomography, Advanced Energy Materials 5 (5) (2015) 1401612. doi:10.1002/aenm.201401612.

[34] P. J. Osswald, S. V. Erhard, A. Noel, P. Keil, F. M. Kindermann, H. Hoster, A. Jossen, Current density distribution in cylindrical li-ion cells during impedance measurements, Journal of Power Sources 314 (2016) 93-101. doi:10.1016/j.jpowsour.2016.02.070.

[35] J. R. Belt, D. M. Bernardi, V. Utgikar, Development and use of a lithium-metal reference electrode in aging studies of lithium-ion batteries, Journal of the Electrochemical Society 161 (6) (2014) A1116-A1126. doi:10.1149/2.062406jes. 
[36] E. McTurk, T. Amietszajew, J. Fleming, R. Bhagat, Thermoelectrochemical instrumentation of cylindrical li-ion cells, Journal of Power Sources 379 (2018) 309-316. doi:10.1016/j.jpowsour.2018.01.060.

[37] G. Zhang, L. Cao, S. Ge, C.-Y. Wang, C. E. Shaffer, C. D. Rahn, In situ measurement of radial temperature distributions in cylindrical liion cells, Journal of the Electrochemical Society 161 (10) (2014) A1499A1507. doi:10.1149/2.0051410jes.

[38] J. Fleming, T. Amietszajew, E. McTurk, D. Greenwood, R. Bhagat, Development and evaluation of in-situ instrumentation for cylindrical li-ion cells using fibre optic sensors, HardwareX 3 (2018) 100-109. doi:10.1016/j.ohx.2018.04.001.

[39] J. N. Reimers, Accurate and efficient treatment of foil currents in a spiral wound li-ion cell, Journal of the Electrochemical Society 161 (1) (2013) A118-A127. doi:10.1149/2.046401jes.

[40] R. Spotnitz, S. Hartridge, G. Damblanc, G. Yeduvaka, D. Schad, V. Gudimetla, J. Votteler, G. Poole, C. Lueth, C. Walchshofer, E. Oxenham, Design and simulation of spirally-wound, lithium-ion cells, ECS Transactions 50 (26) (2013) 209-218. doi:10.1149/05026.0209ecst.

[41] J. N. Reimers, M. Shoesmith, Y. S. Lin, L. O. Valoen, Simulating high current discharges of power optimized li-ion cells, Journal of the Electrochemical Society 160 (10) (2013) A1870-A1884. doi:10.1149/2.094310jes. 
[42] M. Guo, R. E. White, Mathematical model for a spirally-wound lithium-ion cell, Journal of Power Sources 250 (2014) 220-235. doi:10.1016/j.jpowsour.2013.11.023.

[43] K.-J. Lee, K. Smith, A. Pesaran, G.-H. Kim, Three dimensional thermal, electrical-, and electrochemical-coupled model for cylindrical wound large format lithium-ion batteries, Journal of Power Sources 241 (2013) 20-32. doi:10.1016/j.jpowsour.2013.03.007.

[44] W. Zhao, G. Luo, C.-Y. Wang, Effect of tab design on large-format li-ion cell performance, Journal of Power Sources 257 (2014) 70-79. doi:10.1016/j.jpowsour.2013.12.146.

[45] F. Bahiraei, A. Fartaj, G.-A. Nazri, Electrochemical-thermal modeling to evaluate active thermal management of a lithiumion battery module, Electrochimica Acta 254 (2017) 59-71. doi:10.1016/j.electacta.2017.09.084.

[46] D. A. H. McCleary, J. P. Meyers, B. Kim, Three-dimensional modeling of electrochemical performance and heat generation of spirally and prismatically wound lithium-ion batteries, Journal of the Electrochemical Society 160 (11) (2013) A1931-A1943. doi:10.1149/2.023311jes.

[47] K. h. Lee, Product specification: Rechargeable lithium ion battery model: Inr18650 mj1 3500mah (29.07.2016).

URL http: //www.lgchem.com

[48] A. Rheinfeld, S. Kosch, S. V. Erhard, P. J. Osswald, B. Rieger, A. Jossen, Electro-thermal modeling of large format lithium-ion pouch 
cells: A cell temperature dependent linear polarization expression, Journal of The Electrochemical Society 163 (14) (2016) A3046-A3062. doi:10.1149/2.0701614jes.

[49] Feinmetall, Product specification - connector 1860c006_de, url: http://www.feinmetall.de (2017).

[50] I. Zilberman, A. Rheinfeld, A. Jossen, Uncertainties in entropy due to temperature path dependent voltage hysteresis in li-ion cells, Journal of Power Sources 395 (2018) 179-184. doi:10.1016/j.jpowsour.2018.05.052.

[51] P. J. Osswald, M. d. Rosario, J. Garche, A. Jossen, H. E. Hoster, Fast and accurate measurement of entropy profiles of commercial lithium-ion cells, Electrochimica Acta 177 (2015) 270-276. doi:10.1016/j.electacta.2015.01.191.

[52] J. Christensen, V. Srinivasan, J. Newman, Optimization of lithium titanate electrodes for high-power cells, Journal of The Electrochemical Society 153 (3) (2006) A560-A565.

[53] A. Magasinski, P. Dixon, B. Hertzberg, A. Kvit, J. Ayala, G. Yushin, High-performance lithium-ion anodes using a hierarchical bottom-up approach, Nature materials 9 (4) (2010) 353-358. doi:10.1038/nmat2725.

[54] T. Marks, S. Trussler, A. J. Smith, D. Xiong, J. R. Dahn, A guide to liion coin-cell electrode making for academic researchers, Journal of The Electrochemical Society 158 (1) (2011) A51. doi:10.1149/1.3515072.

[55] C. M. Long, M. A. Nascarella, P. A. Valberg, Carbon black vs. black 
carbon and other airborne materials containing elemental carbon: Physical and chemical distinctions, Environmental pollution (Barking, Essex : 1987) 181 (2013) 271-286. doi:10.1016/j.envpol.2013.06.009.

[56] G. Liu, H. Zheng, A. S. Simens, A. M. Minor, X. Song, V. S. Battaglia, Optimization of acetylene black conductive additive and pvdf composition for high-power rechargeable lithium-ion cells, Journal of The Electrochemical Society 154 (12) (2007) A1129. doi:10.1149/1.2792293.

[57] Habib Rahimi-Eichi, Federico Baronti, Mo-Yuen Chow, IEEE International Symposium on Industrial Electronics (ISIE), 2012: 28 - 31 May 2012, Hangzhou Tianyuan Tower Hotel, Hangzhou, China ; proceedings, IEEE, Piscataway, NJ, 2012.

URL http://ieeexplore.ieee.org/servlet/opac?punumber=6230783

[58] M. Mastali, M. Farkhondeh, S. Farhad, R. A. Fraser, M. Fowler, Electrochemical modeling of commercial lifepo 4 and graphite electrodes: Kinetic and transport properties and their temperature dependence, Journal of The Electrochemical Society 163 (13) (2016) A2803-A2816. doi:10.1149/2.1151613jes.

[59] W. M. Dose, V. A. Maroni, M. J. Piernas-Muñoz, S. E. Trask, I. Bloom, C. S. Johnson, Assessment of li-inventory in cycled si-graphite anodes using lifepo 4 as a diagnostic cathode, Journal of The Electrochemical Society 165 (10) (2018) A2389-A2396. doi:10.1149/2.1271810jes.

[60] D. Allart, M. Montaru, H. Gualous, Model of lithium intercalation into graphite by potentiometric analysis with equilibrium and entropy change 
curves of graphite electrode, Journal of The Electrochemical Society 165 (2) (2018) A380-A387. doi:10.1149/2.1251802jes.

[61] T. Ohzuku, Y. Iwakoshi, K. Sawai, Formation of lithium-graphite intercalation compounds in nonaqueous electrolytes and their application as a negative electrode for a lithium ion (shuttlecock) cell, Journal of the Electrochemical Society 140 (9) (1993) 2490-2498.

[62] M. Doyle, Y. Fuentes, Computer simulations of a lithium-ion polymer battery and implications for higher capacity next-generation battery designs, Journal of The Electrochemical Society 150 (6) (2003) A706. doi:10.1149/1.1569478.

[63] D. A. G. Bruggeman, Berechnung verschiedener physikalischer konstanten von heterogenen substanzen. i. dielektrizitätskonstanten und leitfähigkeiten der mischkörper aus isotropen substanzen, Annalen der Physik 416 (7) (1935) 636-664. doi:10.1002/andp.19354160705.

[64] S. Arrhenius, Über die reaktionsgeschwindigkeit bei der inversion von rohrzucker durch säuren, Zeitschrift für Physikalische Chemie 4U (1). doi:10.1515/zpch-1889-0416.

[65] O. V. Valoen, J. N. Reimers, Transport properties of lipf6-based liion battery electrolytes, Journal of The Electrochemical Society 152 (5) (2005) A882-A891.

[66] K. E. Thomas, R. M. Darling, J. Newman, Mathematical modeling of lithium batteries, in: van Schalkwijk W.A., Scrosati B. (eds) Advances in Lithium-Ion Batteries, pp. 345-392. doi:10.1007/0-306-47508-1_13. 
[67] X. Han, M. Ouyang, L. Lu, J. Li, Simplification of physics-based electrochemical model for lithium ion battery on electric vehicle. part ii: Pseudo-two-dimensional model simplification and state of charge estimation, Journal of Power Sources 278 (2015) 814-825. doi:10.1016/j.jpowsour.2014.08.089.

[68] N. Legrand, B. Knosp, P. Desprez, F. Lapicque, S. Raël, Physical characterization of the charging process of a li-ion battery and prediction of li plating by electrochemical modelling, Journal of Power Sources 245 (2014) 208-216. doi:10.1016/j.jpowsour.2013.06.130.

[69] Z. Chu, X. Feng, L. Lu, J. Li, X. Han, M. Ouyang, Nondestructive fast charging algorithm of lithium-ion batteries based on the control-oriented electrochemical model, Applied Energydoi:10.1016/j.apenergy.2017.03.111.

[70] P. Keil, Aging of lithium-ion batteries in electric vehicles, Dissertation, url: http://nbn-resolving.de/urn/resolver.pl?urn:nbn:de:bvb:91diss-20170711-1355829-1-5, Technical University of Munich, München (19.04.2017).

[71] I. Bloom, J. Christophersen, K. Gering, Differential voltage analyses of high-power lithium-ion cells, Journal of Power Sources 139 (1-2) (2005) 304-313. doi:10.1016/j.jpowsour.2004.07.022.

[72] J. Marcicki, X. G. Yang, Model-based estimation of reversible heat generation in lithium-ion cells, Journal of the Electrochemical Society 161 (12) (2014) A1794-A1800. doi:10.1149/2.0281412jes. 
[73] R. E. Williford, V. V. Viswanathan, J.-G. Zhang, Effects of entropy changes in anodes and cathodes on the thermal behavior of lithium ion batteries, Journal of Power Sources 189 (1) (2009) 101-107. doi:10.1016/j.jpowsour.2008.10.078.

[74] R. Yazami, Y. Reynier, Thermodynamics and crystal structure anomalies in lithium-intercalated graphite, Journal of Power Sources 153 (2) (2006) 312-318. doi:10.1016/j.jpowsour.2005.05.087.

[75] V. V. Viswanathan, D. Choi, D. Wang, W. Xu, S. Towne, R. E. Williford, J.-G. Zhang, J. Liu, Z. Yang, Effect of entropy change of lithium intercalation in cathodes and anodes on li-ion battery thermal management, Journal of Power Sources 195 (11) (2010) 3720-3729. doi:10.1016/j.jpowsour.2009.11.103.

[76] K. E. Thomas, J. Newman, Heats of mixing and of entropy in porous insertion electrodes, Journal of Power Sources 119-121 (2003) 844-849. doi:10.1016/S0378-7753(03)00283-0.

[77] P. A. Linford, Lithium ion power generator: a novel system for direct thermal to electric energy conversion, M.sc. thesis, Massachusetts Institute of Technology, Massachusetts (2017).

[78] S. V. Erhard, Mehrdimensionale elektrochemisch-thermische modellierung von lithium-ionen-batterien, Ph.d., Technische Universität München, München (20.04.2017).

[79] K. G. Gallagher, S. E. Trask, C. Bauer, T. Woehrle, S. F. Lux, M. Tschech, P. Lamp, B. J. Polzin, S. Ha, B. Long, Q. Wu, W. Lu, D. W. 
Dees, A. N. Jansen, Optimizing areal capacities through understanding the limitations of lithium-ion electrodes, Journal of the Electrochemical Society 162 (2) (2016) A138-A149. doi:10.1149/2.0321602jes.

[80] S. Kosch, A. Rheinfeld, S. V. Erhard, A. Jossen, An extended polarization model to study the influence of current collector geometry of largeformat lithium-ion pouch cells, Journal of Power Sources 342 (2017) 666-676. doi:10.1016/j.jpowsour.2016.12.110.

[81] I. A. Hunt, Y. Zhao, Y. Patel, J. Offer, Surface cooling causes accelerated degradation compared to tab cooling for lithium-ion pouch cells, Journal of The Electrochemical Society 163 (9) (2016) A1846-A1852. doi:10.1149/2.0361609jes.

[82] W. Polifke, J. Kopitz, Wärmeübertragung: Grundlagen, analytische und numerische Methoden, 2nd Edition, ing - Maschinenbau, Pearson Studium, München, 2009.

[83] VDI-Wärmeatlas: Mit 320 Tabellen, 11th Edition, VDI-Buch, Springer Vieweg, Berlin, 2013. doi:10.1007/978-3-642-19981-3.

URL http://dx.doi.org/10.1007/978-3-642-19981-3

[84] F. A. Wolff, J. H. Dellinger, The electrical conductivity of commercial copper, Proceeding of the American Institute of Electrial Engineers 29 (12) (1910) 1981-2008. doi:10.1109/PAIEE.1910.6660499.

[85] D. G. Giancoli, Physics: Principles with Application, 4th Edition, Prentice Hall College Div, 1995. 
[86] S. C. Chen, C. C. Wan, Y. Y. Wang, Thermal analysis of lithiumion batteries, Journal of Power Sources 140 (1) (2005) 111-124. doi:10.1016/j.jpowsour.2004.05.064.

[87] K. Kanari, K. Takano, Y. Saito, Thermal behavior and simulation of a lithium secondary battery 60 (1996) 65-75.

[88] H. Sun, K. Zhao, Electronic structure and comparative properties of lini x mn y co z o 2 cathode materials, The Journal of Physical Chemistry C 121 (11) (2017) 6002-6010. doi:10.1021/acs.jpcc.7b00810.

[89] D. Bernardi, A general energy balance for battery systems, Journal of The Electrochemical Society 132 (1) (1985) 5. doi:10.1149/1.2113792. 